\title{
Predicting the performance of large-scale forward osmosis module using spatial variation model: Effect of operating parameters including temperature
}

\author{
JungGil Lee ${ }^{\mathrm{a}, \mathrm{b}}$ and Noreddine Ghaffour ${ }^{\mathrm{a},}$, \\ ${ }^{a}$ King Abdullah University of Science and Technology (KAUST), Water Desalination and Reuse Center (WDRC), \\ Biological and Environmental Science \& Engineering Division (BESE), Thuwal 23955-6900, Saudi Arabia, Email: \\ noreddine.ghaffour@kaust.edu.sa \\ ${ }^{b}$ Thermal \& Fluid System R\&D Group, Korea Institute of Industrial Technology, 89 Yangdaegiro-gil, Ipjang-myeon, \\ Seobuk-gu, Cheonan, 331-822, Republic of Korea
}

\begin{abstract}
Forward osmosis (FO) is considered as an energy-efficient process for numerous applications. Although its performance is determined by the spatially varied operation factors and the length of the channel, most of the reported simulation studies rely on length-averaged lumped models. Here, we introduce a one-D model based on heat and mass transfer and transport behavior for both bulk draw and feed channel flows. We find prediction results to be in good agreement with two different experimental results at inlet feed temperatures below $25{ }^{\circ} \mathrm{C}$. However, the difference of water flux $\left(\mathrm{J}_{\mathrm{w}}\right)$ and reverse salt flux (RSF) between measured and predicted data increases when both feed and draw temperatures also increase. Our theoretical simulation study first reveals that the feed temperature near the membrane active layer surface is the main factor for improving water and salt permeabilities. We find that, with a channel width of $0.3 \mathrm{~m}$ and a channel length of $2.5 \mathrm{~m}, \mathrm{~J}_{\mathrm{w}}$ and RSF calculated using the length-averaged based lumped model are overestimated by $13.01 \%$ and $13.12 \%$, respectively, compared to those obtained using our new spatial variation model. Our study demonstrates that the length-averaged based lumped model is not an appropriate simulation model to predict the performance of large-scale FO modules at lower inlet velocities.
\end{abstract}

Keywords: FO simulation, Spatial variation, Length-averaged lumped model, Influence of temperatures, water and salt permeabilities.

\section{Introduction}


Global demand for freshwater is set to exceed supply, due to the rapid urbanization, industrialization, and climate change resulting from global warming [1-3]. The amount of surface water available for use is also insufficient to meet the global demand [3]. Therefore, to mitigate the water scarcity, freshwater is produced by using traditional desalination and wastewater reuse technologies [1,4]. These two areas are growing very rapidly, [1], with a need to develop novel energy efficient technologies to reduce the water production cost and enhance the water quality. Extensive research is being undertaken to improve the overall productivity, quality, and energy efficiency [4]. Among the most recent technologies being developed, those using membranes such as forward osmosis (FO) have received interest due to their feasibility, high productivity and low energy consumption [4]. Reverse osmosis (RO) is recognized as an efficient water treatment process; it has been rapidly and successfully commercialized at a very large scale $[5$, 6]. However, the RO is still facing various operational challenges, such as the need for an extensive pretreatment requiring the use of many chemicals for mitigating the scaling and fouling problems, a high electrical energy consumption $[1,6]$. FO is a natural mass transfer process with much lower energy consumption and reduced use of chemicals [7]. FO uses a dense, hydrophilic, semi-permeable membrane separating the freshwater spontaneously. The process is driven by the difference in osmotic pressure generated from the difference of feed (low) and draw (high) concentrations. This leads to a reduction in energy consumption, compared to traditional pressure-driven membrane separation techniques [8].

Although the FO process cannot be used to produce fresh water in a stand-alone system, it can be used for various applications with dilution and concentration purposes, in water treatment fields including desalination, landfill leachate, acid mine drainage, and oily wastewater plants [913]. For example, FO has found applications in the agricultural field, as a mean to dilute fertilizers for [7,14-17]. To further improve the performance of the FO process, several researchers have worked on the development of novel FO membranes [18-24], the optimization of the draw solution and concentration [10, 25, 26], the design of FO modules [27], and hybrid FO systems [27-30].

Concentration polarization (CP) phenomenon is well-known as the primary challenge leading to an inefficient operation affecting mainly the FO flux. The FO process can have three different configurations: the symmetric mode (symmetric dense membrane), the FO and PRO mode (i.e., FS facing the membrane's active layer and DS facing the porous support layer and vice-versa, 
respectively). Among these configurations, in the FO mode, the structure parameter of the membrane support layer determines the internal CP (ICP) facing the draw solution, whereas the feed flow condition determines the external CP (ECP) facing the feed solution.

Water flux $\left(\mathrm{J}_{\mathrm{w}}\right)$ and reverse salt flux (RSF), as primary indicators of the FO process performance, are closely related to the properties of the membrane, ICP, ECP and the difference of transmembrane osmotic pressure. Due to these complex parameters, it is necessary to develop theoretical prediction models that predict the FO process performance and help to reduce the experimental runs and errors, especially at large module scale. Several theoretical studies of the FO process have been conducted to find the optimal operating conditions or module design, in order to improve the $\mathrm{J}_{\mathrm{w}}$ and lower RSF [31-34]. Examples of such prediction models include those from Lee et al., [35] and Loeb et al., [36] for the FO water flux and the theoretical method fromTiraferri et al., [33] for the characterization of the water and salt permeabilities and the structural parameters of the FO membrane. You et al., [37] also studied the influence of temperature on $\mathrm{J}_{\mathrm{w}}$, both experimentally and theoretically. Chowdhury and McCutcheon [38] studied the influence of the inlet feed temperature on $\mathrm{J}_{\mathrm{w}}$ and $\mathrm{J}_{\mathrm{S}}$ and heat flux across the membrane. They presented the influence of the temperature gradient across the membrane on the FO performance by using general heat flux eqaution. However, they did not consider the temperature gradient which is caused by the heat transfer for axial direction in the channels. In FO system, the solution tempeature can affect the FO performance and it changes along the spatial variation in flow channels due to the heat energy transport across the membrane. Therefore, in order to obtain high accuracy FO simulation data, temperature gradient with the spatial variation needs to be considered.

All the studied theoretical simulations are based on the FO membrane performance, using small lab-scale modules, and they are conducted using a length-averaged lumped model that doesn't take into account spatial variations, in both the draw and feed channels. Although the spatial variation of operating conditions is negligibly small at the lab-scale module, it cannot be neglected for large modules or in multi-stage pilot- scale concepts. This is because the diffusivity of the solutes in the solution and the osmotic pressure vary, depending on the salinity and temperature along the module channel, due to heat and mass transfer. The osmotic pressure is a function of the ion number, salinity, and temperature. The number of theoretical studies that consider spatial variations such as heat and mass transfer, and transport behavior, is low when 
applied to FO, especially coupled with a temperature gradient along the module channel. Our motivation for taking into account the temperature gradient, in our study, is the wide variety of FO niche applications, using FO feed and draw solutions with different temperatures [6-38]. The temperature of the exhausted waste water or impaired quality water from industry or the municipality that could be used as FO feed or draw solution may be higher than the atmospheric temperature, thus impacting on the performance of FO [38-41].

This work aims to develop an accurate, integrated FO simulation model which takes into account the mass, momentum and energy balances on both draw and feed flows coupled with heat and mass transfers on the $\mathrm{J}_{\mathrm{w}}$ and the RSF. Experimental and theoretical investigations are simultaneously performed to develop an accurate simulation model. Predicted results from two different models (the length-averaged lumped model and the spatial variation model presented here) are compared to better understand the differences between results obtained by the two models at various channel widths and lengths. The influence of temperature of the draw and feed sides on the $\mathrm{J}_{\mathrm{w}}$ and $\mathrm{RSF}$, in connection with the different thermal properties, are also investigated. In addition, water and salt permeabilities, at different feed and draw temperatures, are re-estimated. Re-estimated data are mapped to derive the water and salt permeabilities correlations, according to the applied temperatures for accurate prediction. This study allows us to understand, in a comprehensive manner, the influence of the heat and mass transfers and their transport behavior on the FO $\mathrm{J}_{\mathrm{w}}$ and RSF.

\section{Materials and methods}

\subsection{Experimental set-up}

Fig. 1 showed schematic of the FO experimental set-up. Temperatures of the feed and draw solutions are kept constant during the experiments by using temperature controllers (chiller and boiler). Peristaltic pumps supply the draw and feed solutions to both inlet channels, flowing in a counter-current fashion. The initial volume of the draw and feed solutions is $2 \mathrm{~L}$ each. Two conductivity meters measure the conductivities of both the feed and the draw solutions, in real time. Data acquisition is performed via a connection between the computer and the balance and conductivity meters, in real time. The channel dimensions of the FO module are $2 \mathrm{~cm} \mathrm{x} 7 \mathrm{~cm} \mathrm{x}$ $0.2 \mathrm{~cm}$ (width $\mathrm{x}$ length $\mathrm{x}$ height). 
The thicknesses of the TFC-PA membrane's active and support layers $(0.86 \mu \mathrm{m}$ (averaged value) and $99.14 \mu \mathrm{m}$, respectively) are measured using SEM image analysis (Carl Zeiss:

Merlin ${ }^{\mathrm{TM}}$ Field Emision Scanning Electron Microscope), as shown in Fig. 2. The membrane thickness is found to be approximately $100 \pm 1 \mu \mathrm{m}$, measured by a digital micrometer (Digital Micrometer 0.001, $12.7 \mathrm{~mm}$ Electronic Thickness Gauge Depth LCD Measurement). The thermal conductivity of PA is $0.27 \mathrm{~W} / \mathrm{mK}$ [42]. The porosity of the support layer measured using the gravimetric method is $63 \% \pm 5$. The weight of isopropyl alcohol, which has a density of 786 $\mathrm{kg} / \mathrm{m}^{3}$ as an organic solvent in the pores, is employed to measure the porosity of the support layer [43].

The latter is defined as the volume of the pores divided by the total volume of the membrane, and can be expressed as follows:

$\varepsilon_{m}=\frac{\left(w_{1}-w_{2}\right) / D_{i}}{\left(w_{1}-w_{2}\right) / D_{i}+w_{2} / D_{p}}$

where $\mathrm{w}_{1}$ and $\mathrm{w}_{2}$ are the weights of the wet and dried membranes, respectively and $\mathrm{D}_{\mathrm{i}}$ and $\mathrm{D}_{\mathrm{p}}$ are the densities of isopropyl alcohol and polymer, respectively.

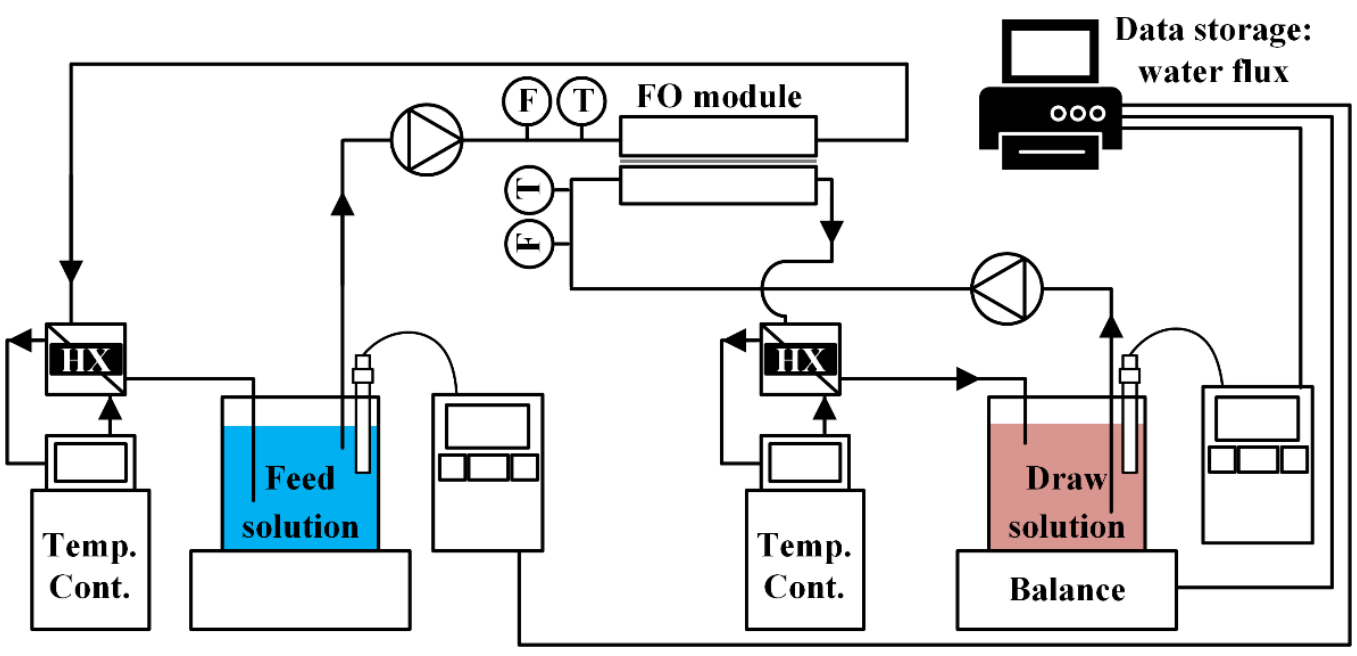

Figure 1. Schematic of the experimental set-up. 


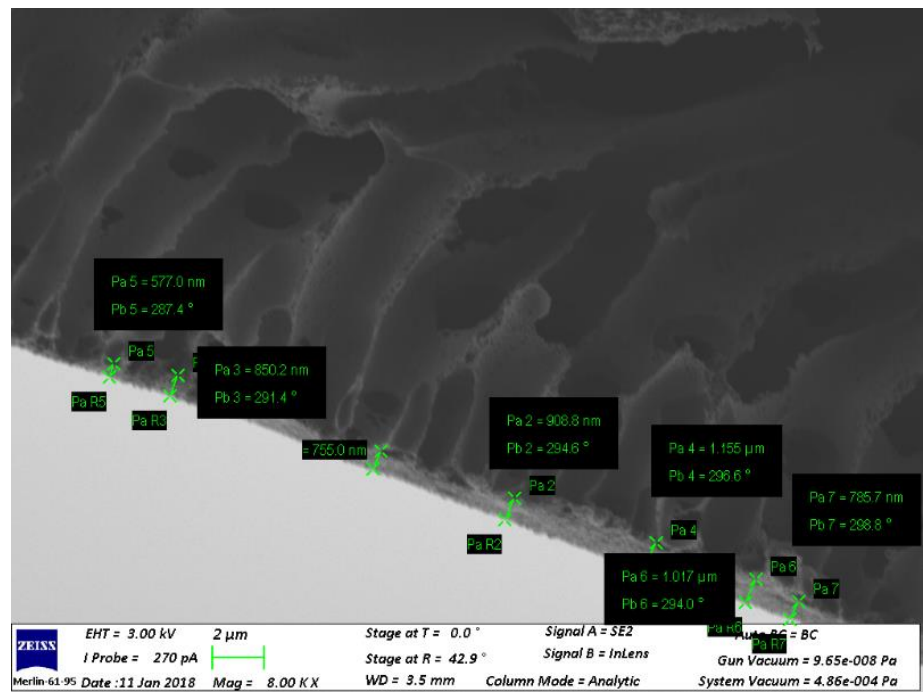

Figure 2. Cross-section SEM image of the TFC-PA membrane's active and support layers provided by Toray Co.

The thermal conductivity of the TFA-PA FO membrane is calculated using Eq. (2).

$k_{\text {overall }}=\left(\frac{\delta_{\text {active }}}{k_{m}}+\frac{\delta_{\text {support }}}{\varepsilon_{\text {support }} k_{w}+\left(1-\varepsilon_{\text {support }}\right) k_{m}}\right)^{-1}$

where $\delta_{\text {active }}$ and $\delta_{\text {support }}$ are the active and support layer thicknesses of the membrane, respectively, $\mathrm{k}_{\text {overall }}, \mathrm{k}_{\mathrm{m}}$, and $\mathrm{k}_{\mathrm{w}}$ are the thermal conductivities of the overall, the membrane, the water, and the support layer, respectively, and $\varepsilon_{\text {support }}$ is the porosity of the support layer.

\section{Theoretical approach}

The main driving force of the FO process is the osmotic pressure difference, which is affected by both the concentration and the temperature between the feed and draw solutions (Fig. 3). The temperature and concentration of the draw and feed sides can vary, due to the heat and mass transfers across the semi-permeable membrane. Furthermore, these variations can influence the overall performance of the FO system. Therefore, in our study, we use a rigorous onedimensional simulation model integrating heat and mass transfers coupled with a transport behavior developed by considering spatial variations in both draw and feed flows. The main assumptions for the simulation study are: (i) conduction and convection heat loss to the ambient is negligible; (ii) internal flows are incompressible in steady state; and (iii) roughness of the membrane surface and module at the draw and feed sides is not considered. 
167 The basic equation of an ideal $\mathrm{J}_{\mathrm{W}}$ in $\mathrm{FO}$ can be expressed as:

$$
J_{W}=A\left(\pi_{D, b}-\pi_{F, b}\right)
$$
pressures of the bulk draw and feed sides, respectively. becomes the following [44]:

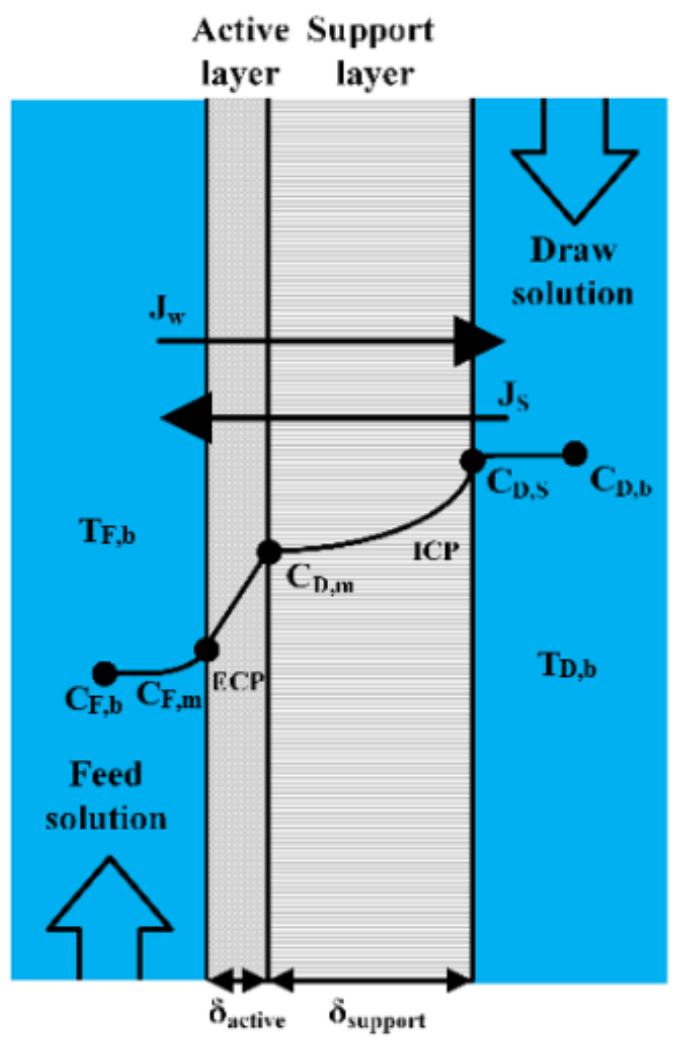

Figure 3. Schematic diagram of the FO process.

where $A$ is the water permeability coefficient of the membrane, $\pi_{\mathrm{D}, \mathrm{b}}$ and $\pi_{\mathrm{F}, \mathrm{b}}$ are the osmotic

Eq. (3) expresses the ideal $\mathrm{J}_{\mathrm{w}}$ without any negative CP effect on the draw or feed sides.

However, in a real operation, CP and RSF do affect the performance of the FO process.

Therefore, the basic equation of $\mathrm{J}_{\mathrm{w}}$ is modified, when considering the ICP (facing draw solution) and ECP (facing feed solution) effects as well as the RSF on the FO performance. It then 
$176 \quad J_{W}=A\left(\frac{\pi_{D, b} \exp \left(-\frac{J_{W} S}{D_{N a C l}}\right)-\pi_{F, b} \exp \left(\frac{J_{W}}{k}\right)}{1+\frac{B}{J_{W}}\left[\exp \left(\frac{J_{W}}{k}\right)-\exp \left(-\frac{J_{W} S}{D_{\text {NaCl }}}\right)\right]}\right)$

177 where $S=\varepsilon_{\text {support }} / \tau \delta_{\text {support }}$ ( $\tau$ is the tortuosity) is the structural parameter of the membrane 178 support layer, $\mathrm{D}_{\mathrm{NaCl}}$ is the bulk solute $(\mathrm{NaCl})$ diffusion coefficient, $\mathrm{k}=\mathrm{ShD}_{\mathrm{NaC}} / \mathrm{d}_{\mathrm{h}}$ (Sh is the 179 Sherwood number) is the mass transfer coefficient, B is the solute $(\mathrm{NaCl})$ permeability 180 coefficient of $\mathrm{FO}$ membrane, and $\pi_{\mathrm{D}, \mathrm{m}}$ and $\pi_{\mathrm{F}, \mathrm{m}}$ are the osmotic pressure of draw and feed 181 adjacent membrane sides, respectively.

In a real operation, the transmembrane concentrations are determined from the negative $\mathrm{CP}$ effects. When the FO mode is used, the ICP appears adjacent to the surface of the transmembrane 184 facing the draw solution, and the ECP occurs adjacent to the surface of the transmembrane facing 185 the feed solution. The transmembrane concentration of draw and feed sides can be calculated 186 using the following equations (Eqs. 5 and 6):

$187 \frac{\pi_{D, m}}{\pi_{D, b}}=\exp \left(-\frac{J_{W} S}{D_{\text {NaCl }}}\right)$

$188 \quad \frac{\pi_{F, m}}{\pi_{F, b}}=\exp \left(\frac{J_{W}}{k}\right)$

189 Similarly, the RSF ( $\left.\mathrm{J}_{\mathrm{SR}}\right)$ can be expressed as [44]:

$190 \quad J_{S R}=B\left(\frac{c_{D, b} \exp \left(-\frac{J_{W} S}{D_{N a C l}}\right)-c_{F, b} \exp \left(\frac{J_{W}}{k}\right)}{1+\frac{B}{J_{W}}\left[\exp \left(\frac{J_{W}}{k}\right)-\exp \left(-\frac{J_{W} S}{D_{\text {NaCl }}}\right)\right]}\right)$

191

192

193

194

195

196

where $\mathrm{c}_{\mathrm{D}, \mathrm{b}}$ and $\mathrm{c}_{\mathrm{F}, \mathrm{b}}$ are the bulk solute concentrations of draw and feed sides, respectively.

The diffusion coefficient of $\mathrm{NaCl}\left(\mathrm{D}_{\mathrm{NaCl}}\right)$ does not vary more than 3\%, within the 0.05-2.0 $\mathrm{M}$ range [44]. The correlation of diffusion coefficient for $\mathrm{NaCl}$, according to the temperature, is then derived by using the provided data in [45] and the linear interpolation, and expressed as:

$$
D_{\text {NaCl }}=0.0419\left(\left(T_{D, b}+T_{F, b}\right) / 2\right)+0.4797\left(10^{-9} \mathrm{~m}^{2} \mathrm{~s}\right)
$$

where $\mathrm{T}_{\mathrm{D}, \mathrm{b}}$ and $\mathrm{T}_{\mathrm{F}, \mathrm{b}}$ are the bulk temperatures of the draw and feed sides, respectively. 
198

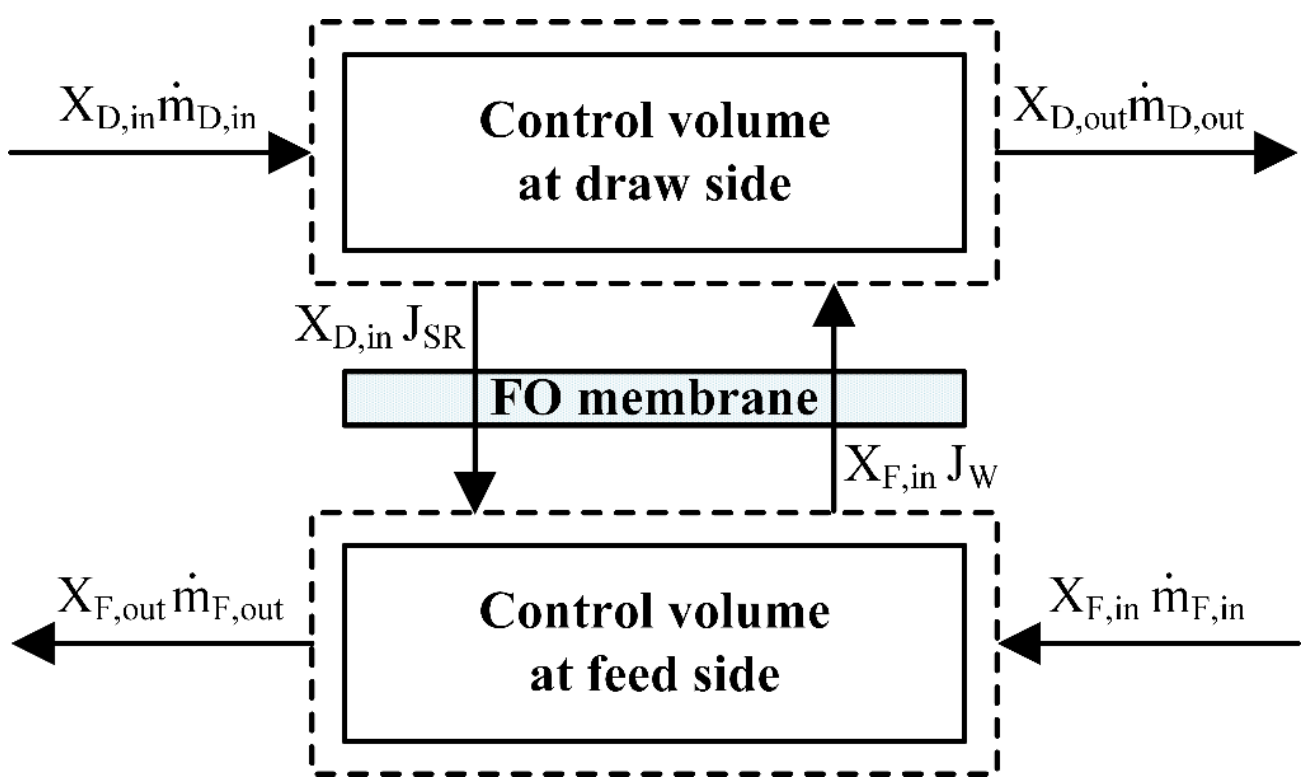

Figure 4. Schematic diagram of mass transfer in the FO process.

A schematic diagram of the mass balance is presented in Fig. 4; the respective equations of mass balance at draw and feed sides can be written as follows:

$$
x_{D, \text { out }} \dot{m}_{D, \text { out }}-x_{D, \text { in }} \dot{m}_{D, \text { in }}=x_{D, \text { in }} J_{S R}-x_{W} J_{W}
$$

$$
x_{F, \text { out }} \dot{m}_{F, \text { out }}-x_{F, \text { in }} \dot{m}_{F, \text { in }}=x_{D, \text { in }} J_{S R}-x_{W} J_{W}
$$

where $x_{W}=0$, due to the assumption that the FO process allows the transport of pure water only across the membrane, $x_{D, \text { in }} x_{F, \text { in }} x_{D, \text { out }}$ and $x_{F, \text { out }}$ are the salinities of inlet draw, inlet feed, outlet draw, and outlet feed, respectively, $\dot{m}_{D, \text { in }} \dot{m}_{F, \text { in }} \dot{m}_{D, \text { out }}$ and $\dot{m}_{F, \text { out }}$ are the flow rates of inlet draw, inlet feed, outlet draw, and outlet feed, respectively.

\subsection{Heat transfer}




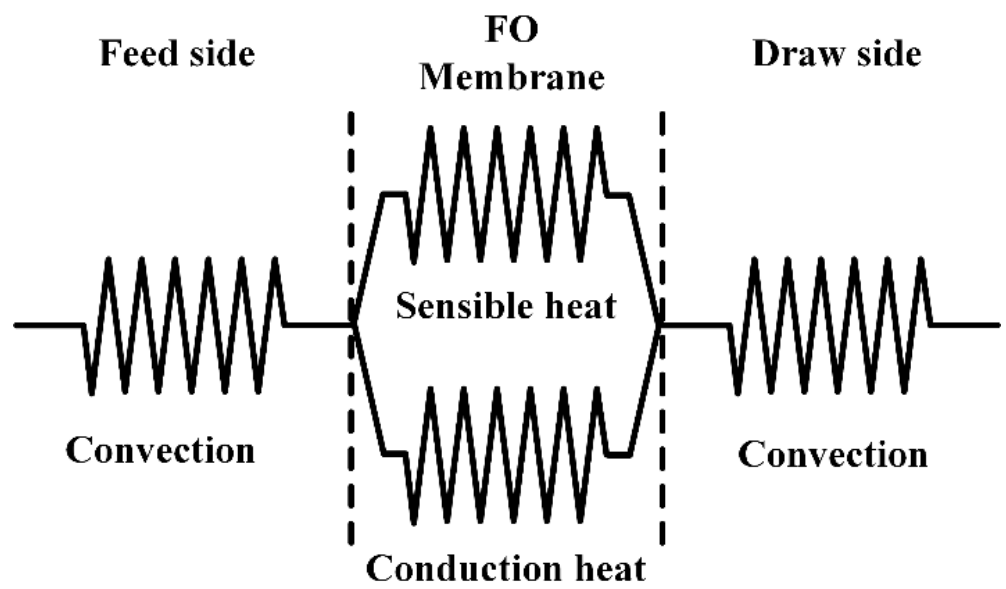

Figure 5. A schematic diagram of heat transfer in the FO process.

Fig. 5 shows a schematic diagram of heat transfer phenomena in the FO process. The heat transfers from the hot to the cold side through the membrane.

Temperature of the feed and draw solutions can affect the difference in osmotic pressure (driving force); it may also affect the water and salt permeabilities of the active membrane layer [46]. If the draw and feed temperatures are different, the heat transfer phenomena should be considered in the FO process. The heat transfers from the hot side to the cold side; this heat transfer is the result of the combination of both the mass transfer ( $\mathrm{J}_{\mathrm{w}}$ and RSF), and the conduction heat transfer with the sensible heat transfer. Thus, the heat transfer equations in the FO process can be expressed by using the following (i, ii, and iii).

\section{(i) Heat transfer from bulk feed to adjacent feed boundary layer}

$Q_{F}=h_{F}\left(T_{F, b}-T_{F, m}\right)$

where $\mathrm{T}_{\mathrm{F}, \mathrm{b}}$ and $\mathrm{T}_{\mathrm{F}, \mathrm{m}}$ are the bulk and transmembrane temperatures at feed side, respectively, and $\mathrm{h}_{\mathrm{F}}$ is the convection heat transfer coefficient calculated by a combination of Reynolds number, $\mathrm{Re}_{\mathrm{i}}$ and Nusselt number, Nu. It can be expressed by the following equation:

$h_{i}=\frac{N u_{i} \cdot L}{d_{h}} \quad i=$ draw and feed sides 
$N u_{i}=1.85\left(\operatorname{Re}_{i} \operatorname{Pr}_{i} \frac{d_{h}}{L}\right)^{0.33} \quad($ laminar flow, $\operatorname{Re}<2300)$

$N u_{i}=0.023 \operatorname{Re}_{i}^{0.75} \operatorname{Pr}_{i}^{0.33} \quad$ (turbulent flow, $\operatorname{Re}>2300$ )

231 where $\mathrm{L}$ is module length, and $\operatorname{Pr}_{i}$ is the Prandtl number.

232

233 (ii) Heat transfer across the membrane

$234 Q_{m}=\left(J_{W} c_{p}+k_{\text {overall }}\right)\left(T_{F, m}-T_{D, \mathrm{~m}}\right)$

235 where $c_{p}$ is the heat capacity, and $\mathrm{T}_{\mathrm{D}, \mathrm{m}}$ is the transmembrane temperature at draw side.

236

237 (iii) Heat transfer from the adjacent draw boundary layer to feed bulk

$238 Q_{D}=h_{D}\left(T_{D, m}-T_{D, b}\right)$

239 where $h_{D}$ and $T_{D, b}$ are the convection heat transfer coefficient and the bulk temperature at draw

240 side, respectively.

241 At steady state, the overall heat transfer through the whole FO process is given by:

$242 Q_{F}=Q_{m}=Q_{D}$

243

244

3.3 Transport behavior

245 At both draw and feed sides, the momentum, mass, species and energy balances can be expressed

246 by integrated differential equations for the pressure, velocity, salinity and temperature, as

247 follows:

$248 \quad \frac{d P_{i}}{d z}=-\frac{3 \mu_{i}}{h_{c, i}^{2}} v_{i}$

$249 \quad \frac{d\left(\rho_{i} v_{i}\right)}{d z}=-\frac{\left(J_{W}-J_{S R}\right)}{h_{c, i}}$

$250 \quad \frac{d\left(\rho_{i} v_{i} x_{i}\right)}{d z}=-\frac{\left(x_{W} J_{W}-x_{D} J_{S R}\right)}{h_{c}}$

$251 \quad \frac{d\left(\rho_{i} v_{i} c_{p, i} T_{i}\right)}{d z}=-\frac{Q_{i}}{h_{c, i}}$

252 where the subscription $\mathrm{i}$ is the draw (D) or feed $(\mathrm{F}), \mu$ is the viscosity, $\rho$ is the density, $v$ is the 
253 velocity, $h_{c}$ is the channel height, and $\mathrm{dz}$ is the grid size.

254 Boundary conditions for the pressure, velocity, salinity, and temperature, at both draw and 255 feed sides, respectively, are as follows:

$256 \quad P_{D}(\mathrm{~L})=P_{0}, v_{D}(0)=v_{D, \text { in }}, \mathrm{x}_{D}(0)=x_{D, \text { in }}, T_{D}(0)=T_{D, \text { in }}$

$257 \quad P_{F}(0)=P_{0}, v_{F}(L)=v_{F, \text { in }}, \mathrm{x}_{F}(L)=x_{F, \text { in }}, T_{F}(L)=T_{F, \text { in }}$

258 where $\mathrm{P}_{0}$ is the atmospheric pressure.

259

260

261

262

263

264

265

266

267

268

269

270

271

272

273

274

275

\section{Modeling procedure}

Fig. 6 presents a schematic diagram of the solution procedure. The set of integrated ordinary differential equations, for both draw and feed sides, are discretized by using the finite volume method (FVM) and calculated using both the boundary conditions at the draw and feed sides and the characterization of the FO membrane for mass transfer. Broyden's method is used to solve the system of ordinary differential equations.

\section{Results and discussion}

\subsection{Model validation}

In order to validate our spatial variation model, predicted results are compared with measured data reported in the literature [44]. Fig. 7 presents both experimental and simulated results of the flux and the RSF, at various draw concentrations. The water and salt permeabilities and structural parameter of the FO membrane that were used in our study are $1.23 \mathrm{kgm}^{-2} \mathrm{~h}^{-1} \mathrm{bar}^{-1}, 0.196 \mathrm{kgm}^{-2} \mathrm{~h}^{-}$ 1 , and $328 \mu \mathrm{m}$, respectively [44]. We find the predicted data are well matched with the experimental data, at constant inlet draw and feed temperatures of $25^{\circ} \mathrm{C}$ and velocity of 17.1 $\mathrm{cm} / \mathrm{s}$. 


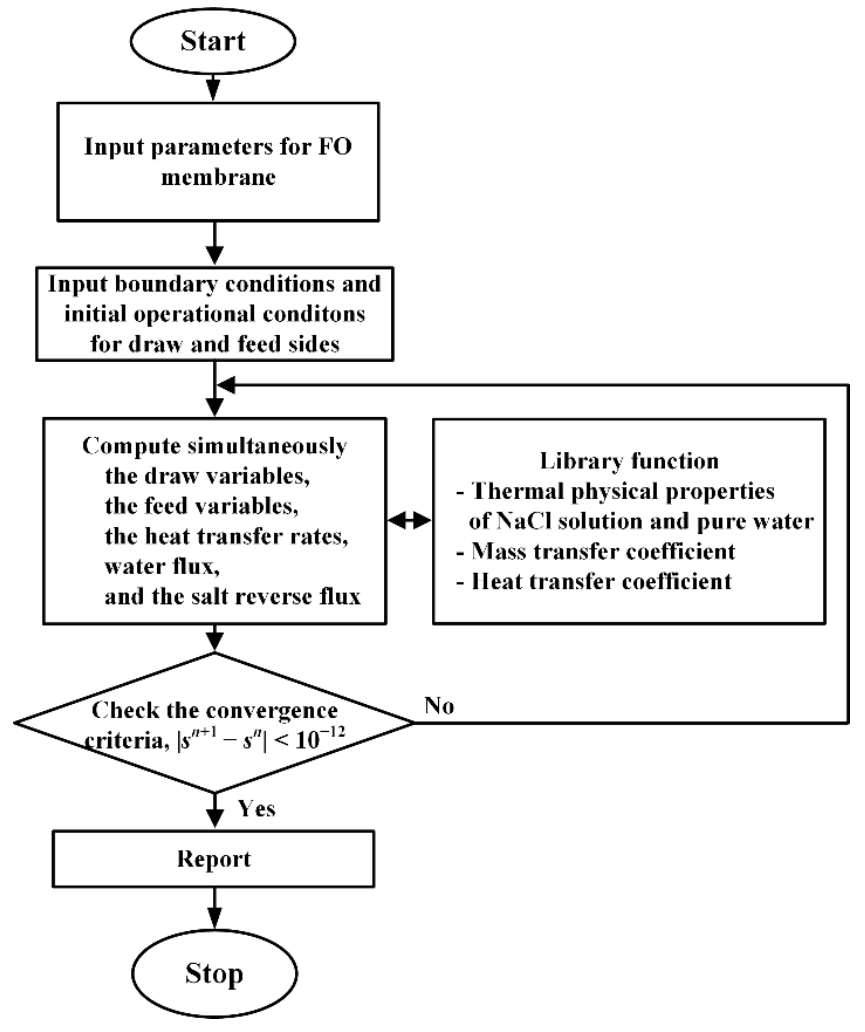

Figure 6. Schematic diagram of the solution procedure.

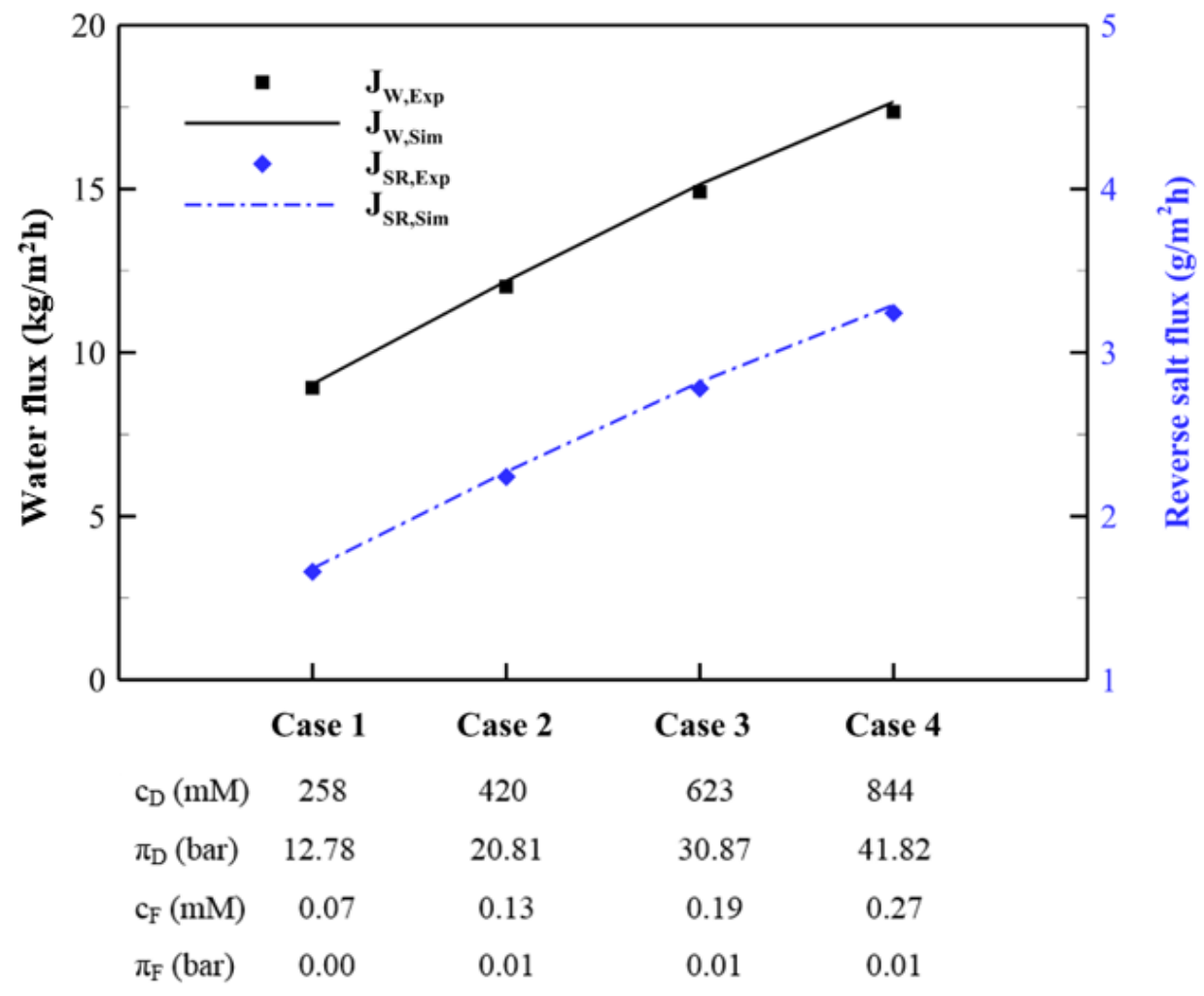


Figure 7. Effect of the inlet draw and feed concentrations on $J_{w}$ and RSF (experimental [44] and simulated), at constant inlet draw and feed temperatures and velocities of $25^{\circ} \mathrm{C}$ and $17.1 \mathrm{~cm} / \mathrm{s}$, respectively.

Table 1 presents a comparison of real data with predicted data, with a length-averaged lumped model and with our model. Details of the operating conditions (case 1 to case 4 ) can be seen in Fig. 7. As shown in the table 1, predicted data for $J_{\mathrm{w}}$ and the RSF, using a lengthaveraged lumped model, have average errors of $2.1 \%$ and $2.4 \%$, respectively. On the other hand, average errors of $1.5 \%$ and $1.4 \%$, are obtained when using our new model of spatial variation for both draw and feed channels. We find that the difference obtained by the two different models is insignificant, due to the negligible concentration gradient along the feed and draw channels, especially on short channel length. This is because the $\mathrm{J}_{\mathrm{w}}$ and the RSF are much smaller than the inlet draw and feed flow rates.

Table 1. Influence of inlet draw and feed salinities on the flux and RSF, for both measured and predicted values using either the length-averaged lumped model our spatial variation model).

\begin{tabular}{|c|c|c|c|c|c|c|c|c|c|}
\hline Stage & $\begin{array}{l}\text { Real } \\
\text { (St.) }\end{array}$ & $\begin{array}{l}\text { Length- } \\
\text { averaged } \\
\text { lumped } \\
\text { model }\end{array}$ & $\begin{array}{c}\text { Current } \\
\text { developed } \\
\text { spatial } \\
\text { variation } \\
\text { model }\end{array}$ & & $\begin{array}{l}\text { tive } \\
\text { rence }\end{array}$ & $\begin{array}{l}\text { Real } \\
\text { (St.) }\end{array}$ & $\begin{array}{l}\text { Length- } \\
\text { averaged } \\
\text { lumped } \\
\text { model }\end{array}$ & $\begin{array}{c}\text { Current } \\
\text { developed } \\
\text { spatial } \\
\text { variation } \\
\text { model }\end{array}$ & $\begin{array}{c}\text { Relative } \\
\text { Difference }\end{array}$ \\
\hline & \multicolumn{3}{|c|}{$\mathrm{JW}\left(\mathrm{kg} \cdot \mathrm{m}^{-2} \mathrm{~h}^{-1}\right)$} & $(\%)$ & $(\%)$ & \multicolumn{3}{|c|}{$\mathrm{J}_{\mathrm{SR}}\left(\mathrm{g} \cdot \mathrm{m}^{-2} \mathrm{~h}^{-1}\right)$} & $(\%)$ \\
\hline Case1 & 8.92 & 9.04 & 9.04 & 1.35 & 1.35 & 1.66 & 1.63 & 1.68 & 1.81 \\
\hline Case2 & 12.01 & 11.64 & 12.18 & 3.08 & 1.42 & 2.24 & 2.20 & 2.27 & 1.79 \\
\hline Case3 & 14.9 & 15.03 & 15.14 & 0.87 & 1.61 & 2.78 & 2.6 & 2.82 & 3.24 \\
\hline Case4 & 17.35 & 16.81 & 17.65 & 3.11 & 1.73 & 3.24 & 3.33 & 3.29 & 2.78 \\
\hline
\end{tabular}

Additionally, in order to validate our own experimental results with prediction data, using our spatial variation model, a validation of the model is performed at various inlet draw salinities. The TFC-PA FO membrane manufactured by Toray Korea is used in all experiments and simulations. Experiments are conducted four times under similar operational conditions to assess the reproducibility of the system performance. The uncertainty of the measured water fluxes is lower than $\pm 10 \%$.

Fig. 8 presents the experimental and predicted results of flux and RSF for our study that were obtained for an inlet draw and feed temperatures of $20^{\circ} \mathrm{C}$, inlet draw and feed flow rates of 0.4 
$\mathrm{L} / \mathrm{min}$, under various inlet draw concentrations ranging from $17.5 \mathrm{~g} / \mathrm{L}$ to $87.5 \mathrm{~g} / \mathrm{L} \mathrm{NaCl}$, using deionized water (DI) as feed solution. A, B and $\mathrm{S}$ values are $5.964 \mathrm{E}-7 \mathrm{~m} / \mathrm{s} / \mathrm{bar}, 1.805 \mathrm{E}-7 \mathrm{~m} / \mathrm{s}$ and 3.76E-4 m, respectively; the predicted results which were calculated by the spatial varation model are in good agreement with the experimental data. As shown in Fig. 8, at with a high draw solution, the increase in the $\mathrm{J}_{\mathrm{w}}$ and RSF are lower than those obtained for a lower range of draw solution due to the CP effect.

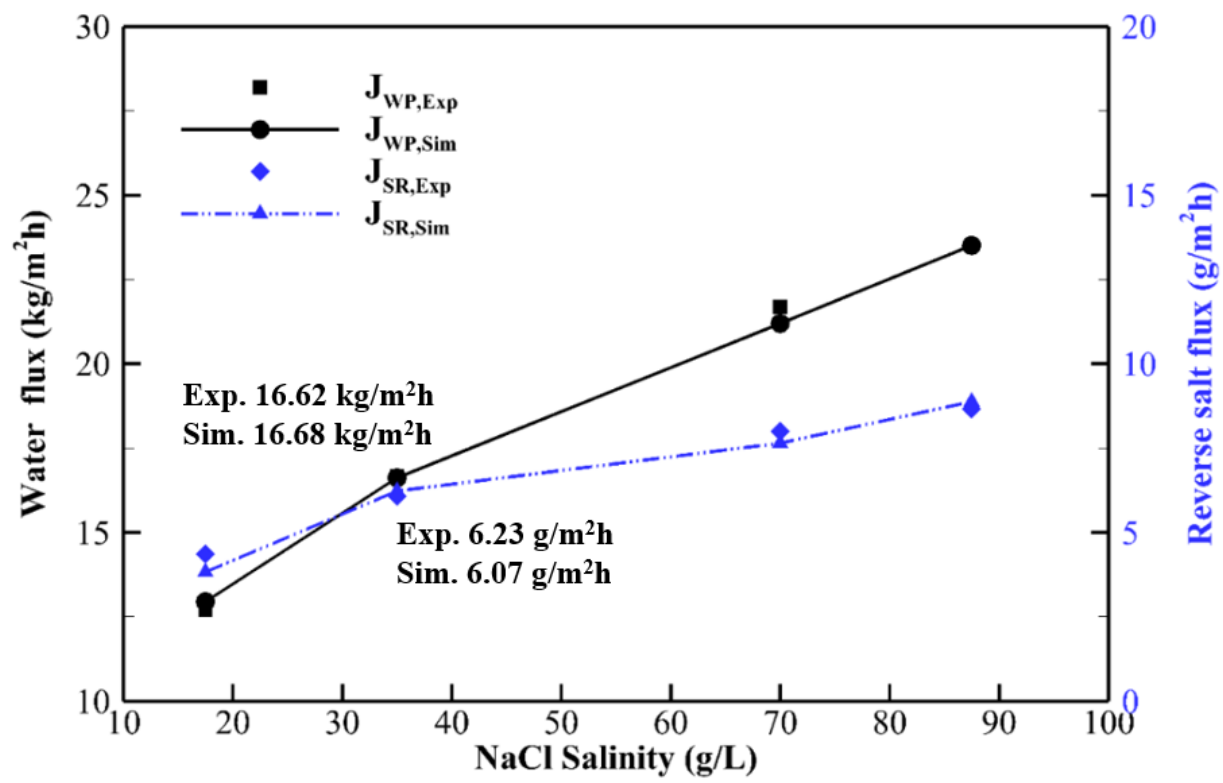

Figure 8. Influence of the inlet draw $\mathrm{NaCl}$ salinity on flux and $\mathrm{RSF}$, at constant inlet draw solution and feed temperatures of $20^{\circ} \mathrm{C}$ and constant inlet draw solution and feed flow rates of $0.4 \mathrm{~L} / \mathrm{min}$.

\subsection{Influence of draw and feed temperatures}

In this section, experimental and theoretical studies are performed with the goal of better understanding the influence of the inlet draw an feed temperatures $\left(20^{\circ} \mathrm{C}-40^{\circ} \mathrm{C}\right)$ on the $\mathrm{J}_{\mathrm{w}}$ and the RSF, at constant inlet draw and feed flow rates of $0.4 \mathrm{~L} / \mathrm{min}(\mathrm{A}, \mathrm{B}$, and $\mathrm{S}$ values of 5.964E-7 $\mathrm{m} / \mathrm{s} /$ bar, $1.805 \mathrm{E}-7 \mathrm{~m} / \mathrm{s}$ and $3.76 \mathrm{E}-4 \mathrm{~m}$, respectively, and obtained experimentally using an inlet draw and a feed temperature of $20{ }^{\circ} \mathrm{C}$ (Fig. 9). Our spatial variation model is used to estimate the predicted results. The experimental results were reproducible within an experimental error of $10 \%$ (experiments conducted four times). When the inlet draw temperature increases from $20^{\circ} \mathrm{C}$ to $40^{\circ} \mathrm{C}$, at a constant inlet feed temperature of $20^{\circ} \mathrm{C}$, the measured $\mathrm{J}_{\mathrm{w}}$ increases from 16.62 
$324 \mathrm{~kg} / \mathrm{m}^{2} \mathrm{~h}$ to $21.15 \mathrm{~kg} / \mathrm{m}^{2} \mathrm{~h}$, and the predicted values also increase from $16.68 \mathrm{~kg} / \mathrm{m}^{2} \mathrm{~h}$ to 20.06

$325 \mathrm{~kg} / \mathrm{m}^{2} \mathrm{~h}$. The maximum relative error percentage is $6.26 \%$, at the highest draw solution

326 temperature of $40^{\circ} \mathrm{C}$. At the same time, the measured RSF increases from $6.23 \mathrm{~g} / \mathrm{m}^{2} \mathrm{~h}$ to 6.82

$327 \mathrm{~kg} / \mathrm{m}^{2} \mathrm{~h}$ and the predicted values also increase from $6.06 \mathrm{~g} / \mathrm{m}^{2} \mathrm{~h}$ to $6.84 \mathrm{~g} / \mathrm{m}^{2} \mathrm{~h}$. The maximum

328 relative error for RSF (2.82\%) is observed at the lowest inlet draw and feed temperatures

$329\left(20^{\circ} \mathrm{C}\right)$.

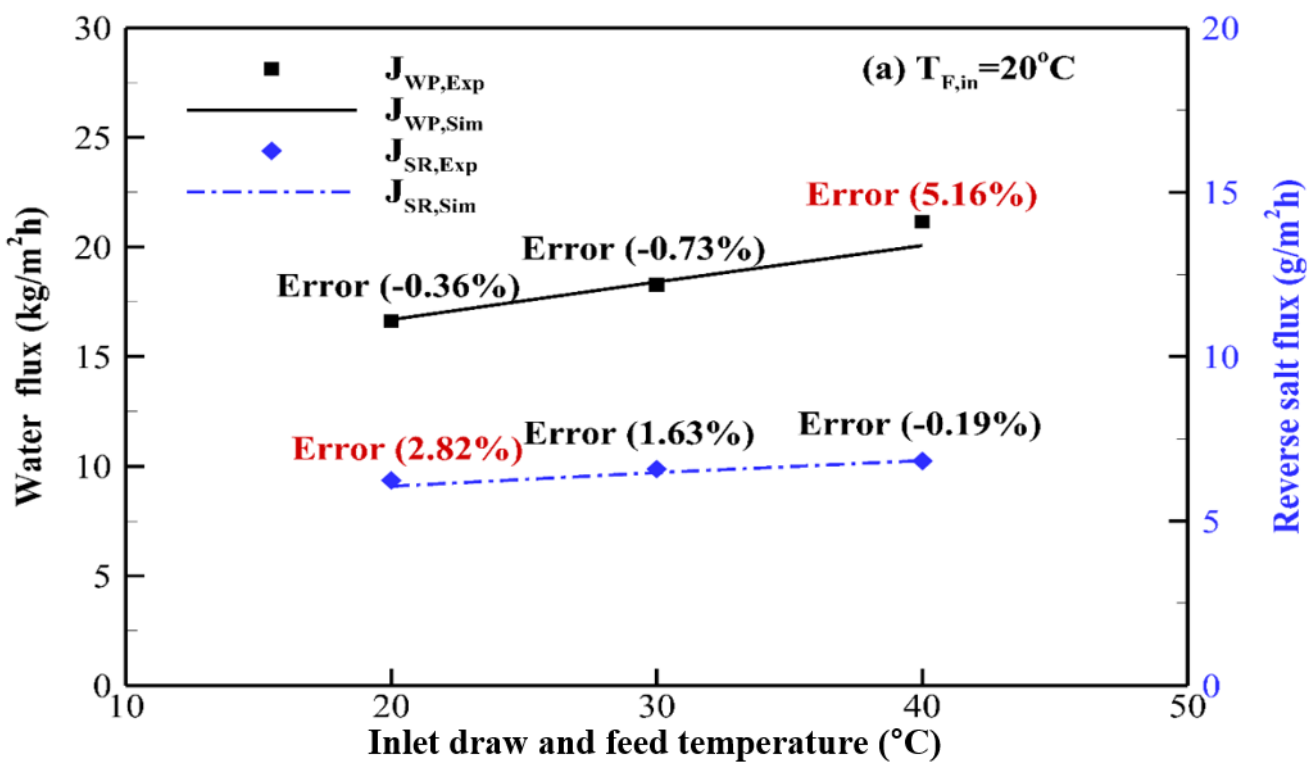

330

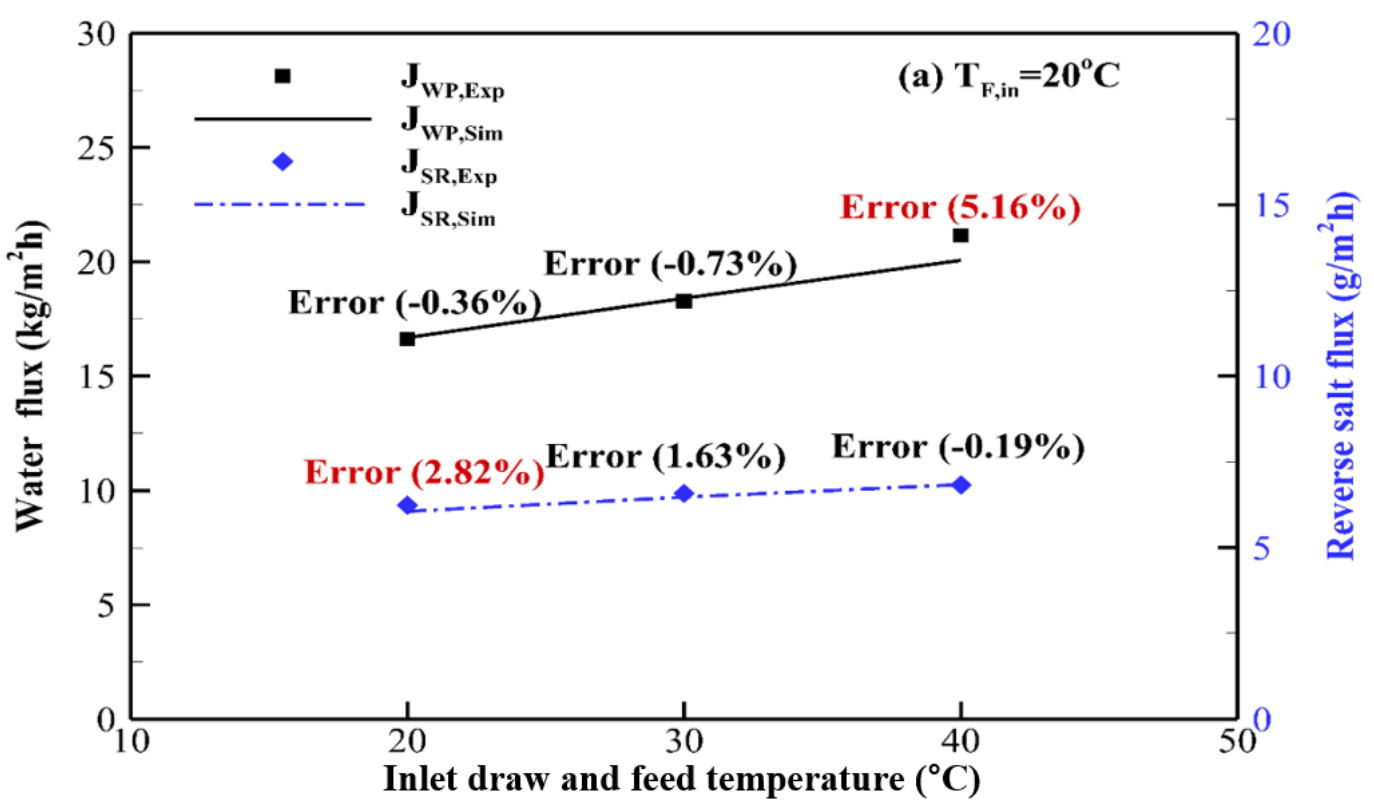




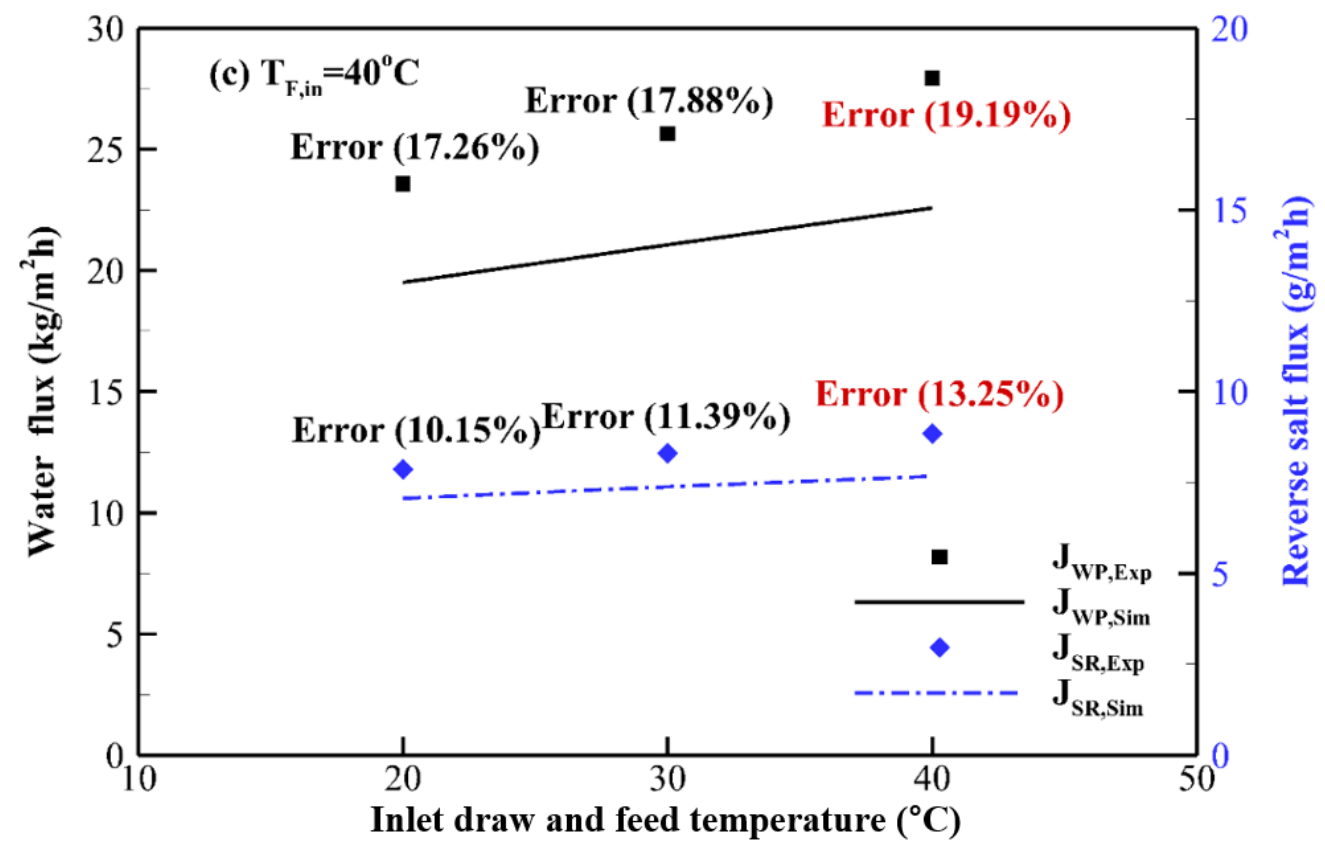

Figure 9. Influence of the inlet draw and feed temperatures ranging from (a) $20^{\circ} \mathrm{C}$ (b) $30^{\circ} \mathrm{C}$ and (c) $40{ }^{\circ} \mathrm{C}$ on the $\mathrm{J}_{\mathrm{WP}}$ and the RSF (measured and predicted), at inlet draw and feed flow rates of $0.4 \mathrm{~L} / \mathrm{min}$ (A, B and S values obtained by our experiments were $5.964 \mathrm{E}-7 \mathrm{~m} / \mathrm{s} / \mathrm{bar}, 1.805 \mathrm{E}-7 \mathrm{~m} / \mathrm{s}$ and 3.76E-4 m, respectively).

Although the average driving force (osmotic pressure difference) only increases by approximately $3 \%$ (from 29.36 bar to 31.27 bar), when increasing the inlet draw temperature

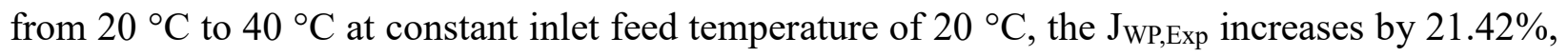
due to the increase of $\mathrm{NaCl}^{\prime} \mathrm{s}$ diffusivity as the inlet draw temperature increases. A similar trend was reported by previous research studies [44] that showed that an increase of the draw and feed temperatures led to higher $\mathrm{J}_{\mathrm{WP} \text {,Exp }}$ and reverse salt flux values (more than anticipated), due to an increase in both feed and draw osmotic pressures and a higher diffusivity of $\mathrm{NaCl}$. According to previous published study [45], the increase of the $\mathrm{J}_{\mathrm{WP} \text {,exp }}$ and the RSF, when increasing the temperature by a higher than the increase of the driving force, can be explained by a decrease of viscosity, increase of the diffusion coefficient and increase of the number of water molecules, due to an increase of temperature. However, when a constant inlet draw temperature of $40^{\circ} \mathrm{C}$ is used, the $J_{\text {WP,Exp }}$ increases from $23.57 \mathrm{~kg} / \mathrm{m}^{2} \mathrm{~h}$ to $27.93 \mathrm{~kg} / \mathrm{m}^{2} \mathrm{~h}(18 \%)$, as the inlet feed temperature increases from $20^{\circ} \mathrm{C}$ to $40^{\circ} \mathrm{C}$. Meanwhile, the RSF increases from $7.86 \mathrm{~g} / \mathrm{m}^{2} \mathrm{~h}$ to $8.84 \mathrm{~g} / \mathrm{m}^{2} \mathrm{~h}$, under similar conditions. The increase of the flux and the RSF (measured) is found 
unexpectedly higher than that obtained with predicted results when considering an increase of the $\mathrm{NaCl}$ 's diffusivity as the inlet feed temperature increases. With our current estimation, the increased $\mathrm{NaCl}$ diffusivity is considered as an estimated correlation (Eq.8), according to the increase of the draw and feed temperatures, together with the module channel. The maximum difference between measured and predicted results, for the $\mathrm{J}_{\mathrm{WP}}$ and that RSF are $19.19 \%$ and $13.25 \%$, for inlet draw and feed temperatures of $40^{\circ} \mathrm{C}$. These results indicate that the feed temperature facing the active layer may affect the pore size of the active layer, as well as the difference of osmotic pressure and $\mathrm{NaCl}$ diffusivity. This hypothesis was previously presented by Goosen et al. [46] whose work revealed a change in the membrane's pore size when the feed solution temperature increases from $30^{\circ} \mathrm{C}$ to $40{ }^{\circ} \mathrm{C}$. Other studies also found an optimum $\mathrm{J}_{\mathrm{w}}$ and RSF under different draw solution temperatures [47]. In our study, we also find that the temperature near the membrane surface affects more the $\mathrm{J}_{\mathrm{w}}$ and RSF than the bulk temperatures (Fig. 10).

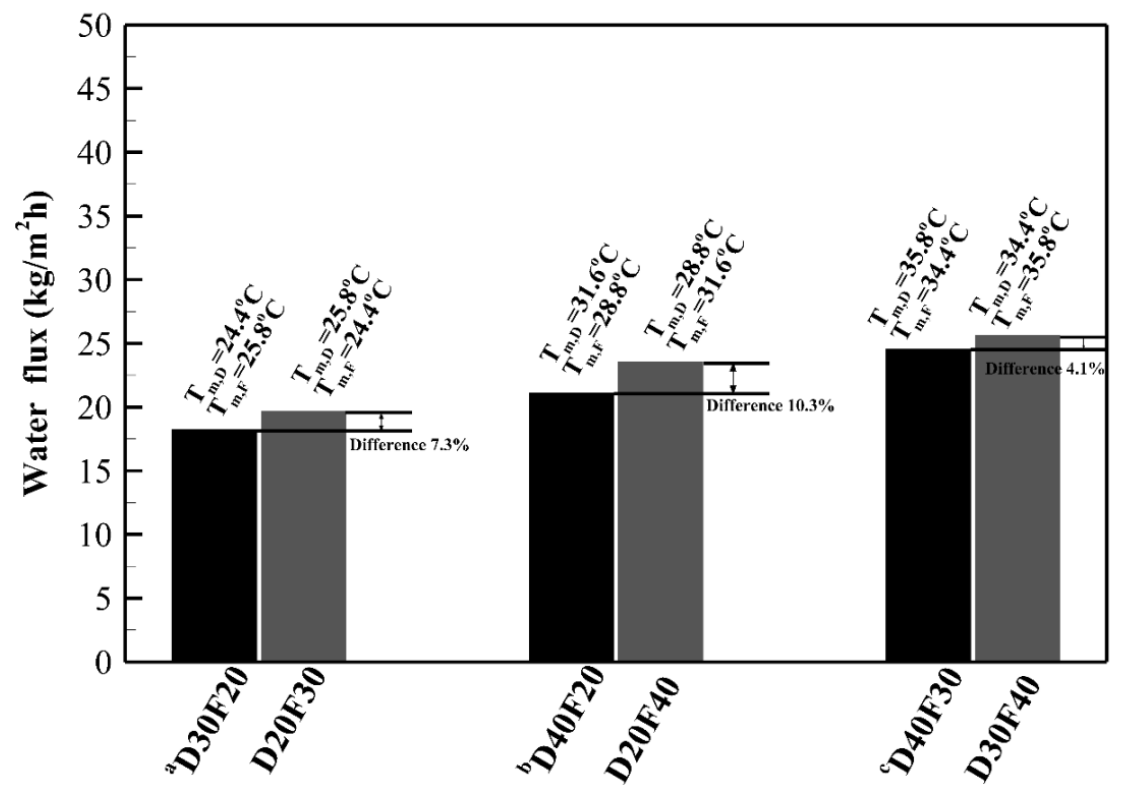

Figure 10. Influence of the feed and draw temperatures predicted on the deviation of measured water flux.

${ }^{\mathrm{a} D} \mathrm{D} 30 \mathrm{~F} 20$ means draw temperature of $30^{\circ} \mathrm{C}$ and feed temperature of $20^{\circ} \mathrm{C}$, and vice versa, ${ }^{\mathrm{b}} \mathrm{D} 40 \mathrm{~F} 20$ means draw temperature of $40^{\circ} \mathrm{C}$ and feed temperature of $20^{\circ} \mathrm{C}$, and vice versa, and ${ }^{\circ} \mathrm{D} 40 \mathrm{~F} 30$ means draw temperature of $40{ }^{\circ} \mathrm{C}$ and feed temperature of $30^{\circ} \mathrm{C}$, and vice vera. 
We find the measured $\mathrm{J}_{\mathrm{w}}$ and RSF values to be very close (less than $7 \%$ difference) at $30^{\circ} \mathrm{C}$ and $20^{\circ} \mathrm{C}$ of the bulk draw and feed temperatures, respectively, in comparison to those obtained at $20^{\circ} \mathrm{C}$ and $30^{\circ}$, respectively. The transmembrane temperature of the draw and feed sides are estimated to be $25.7^{\circ} \mathrm{C}$ and $24.4^{\circ} \mathrm{C}$ for the two cases, respectively. Moreover, when tested at $40^{\circ} \mathrm{C}$ (bulk draw) and $30^{\circ} \mathrm{C}$ (bulk feed), we obtain $\mathrm{J}_{\mathrm{w}}$ and RSF values that are also very similar (less than $4 \%$ difference) to those at $30^{\circ} \mathrm{C}$ (bulk draw) and $40^{\circ} \mathrm{C}$ (bulk feed). We estimate the temperatures adjacent to the membrane's draw and feed sides to be $35.7^{\circ} \mathrm{C}$ and $34.4^{\circ} \mathrm{C}$, respectively. Similarly, at $40^{\circ} \mathrm{C}$ (bulk draw) and $20^{\circ} \mathrm{C}$ (bulk feed), the $\mathrm{J}_{\mathrm{w}}$ and RSF values were also close (less than $11 \%$ difference) as compared to those at $20^{\circ} \mathrm{C}$ (bulk draw) and $40^{\circ} \mathrm{C}$ (bulk feed). In this case, the estimated transmembrane temperatures of feed and draw sides were $31.5^{\circ} \mathrm{C}$ and $28.8^{\circ} \mathrm{C}$, respectively. Furthermore, at a higher temperature near the feed side of the membrane surface for all cases, the flux and RSF values were always higher compared to those at the draw side. We also found that the increase in feed temperature facing the active layer resulted in higher $\mathrm{J}_{\mathrm{w}}$ and RSF as compared to that of draw temperature.

To determine the correlations of the water and salt permeabilities as a function of the draw and feed temperatures, these parameters were re-estimated by the iteration method. In this study, we assumed the change of the properties of structural parameter of the membrane support layer with temperature to be small, because the support layer has much larger pore size, porosity and thickness compared to the active layer. The two parameters A and B in Eqs. (4) and (7), respectively, were estimated from water and salt fluxes experimental data by using the iteration method for solving minimization problems subject to linear equality constraints within the current developed spatial variation model.

Table 2. Re-estimated water (A) and salt (B) permeabilities according to the inlet draw and feed temperatures, at a fixed structural parameter $(\mathrm{S}) . \mathrm{S}=3.76 \mathrm{E}-04 \mathrm{~m}$ in all cases.

\begin{tabular}{cccccccccc}
\hline & Case 1 & Case 2 & Case 3 & Case 4 & Case 5 & Case 6 & Case 7 & Case 8 & Case 9 \\
\hline & $\begin{array}{c}\mathrm{TD}: 20^{\circ} \mathrm{C} \\
\mathrm{TF}: 20^{\circ} \mathrm{C}\end{array}$ & $\begin{array}{c}\mathrm{TD}: 30^{\circ} \mathrm{C} \\
\mathrm{TF}: 20^{\circ} \mathrm{C}\end{array}$ & $\begin{array}{c}\mathrm{TD}: 40^{\circ} \mathrm{C} \\
\mathrm{TF}: 20^{\circ} \mathrm{C}\end{array}$ & $\begin{array}{c}\mathrm{TD}: 20^{\circ} \mathrm{C} \\
\mathrm{TF}: 30^{\circ} \mathrm{C}\end{array}$ & $\begin{array}{c}\mathrm{TD}: 30^{\circ} \mathrm{C} \\
\mathrm{TF}: 30^{\circ} \mathrm{C}\end{array}$ & $\begin{array}{c}\mathrm{TD}: 40^{\circ} \mathrm{C} \\
\mathrm{TF}: 30^{\circ} \mathrm{C}\end{array}$ & $\begin{array}{c}\mathrm{TD}: 20^{\circ} \mathrm{C} \\
\mathrm{TF}: 40^{\circ} \mathrm{C}\end{array}$ & $\begin{array}{c}\mathrm{TD}: 30^{\circ} \mathrm{C} \\
\mathrm{TF}: 40^{\circ} \mathrm{C}\end{array}$ & $\begin{array}{c}\mathrm{TD}: 40^{\circ} \mathrm{C} \\
\mathrm{TF}: 40^{\circ} \mathrm{C}\end{array}$ \\
\hline $\begin{array}{c}\mathrm{A} \\
(\mathrm{m} / \mathrm{s} / \\
\text { bar })\end{array}$ & $5.96 \mathrm{E}-7$ & $6.05 \mathrm{E}-7$ & $7.14 \mathrm{E}-7$ & $7.01 \mathrm{E}-7$ & $7.75 \mathrm{E}-7$ & $8.43 \mathrm{E}-7$ & $8.71 \mathrm{E}-7$ & $9.06 \mathrm{E}-7$ & $9.62 \mathrm{E}-7$ \\
\hline $\begin{array}{c}\mathrm{B} \\
(\mathrm{m} / \mathrm{s})\end{array}$ & $1.81 \mathrm{E}-7$ & $1.82 \mathrm{E}-7$ & $1.93 \mathrm{E}-7$ & $2.19 \mathrm{E}-7$ & $2.30 \mathrm{E}-7$ & $2.27 \mathrm{E}-7$ & $2.58 \mathrm{E}-7$ & $2.62 \mathrm{E}-7$ & $2.71 \mathrm{E}-7$ \\
\hline
\end{tabular}




\begin{tabular}{|c|c|c|c|c|c|c|c|c|c|}
\hline $\begin{array}{c}\text { JW,exp } \\
(\mathrm{kg} / \\
\left.\mathrm{m}^{2} \mathrm{~h}\right)\end{array}$ & 16.62 & 18.27 & 21.15 & 19.71 & 22.18 & 24.58 & 23.57 & 25.64 & 27.93 \\
\hline $\begin{array}{l}J W, \operatorname{sim} \\
\left(\mathrm{g} / \mathrm{m}^{2} \mathrm{~h}\right)\end{array}$ & 16.67 & 18.27 & 21.15 & 19.71 & 22.18 & 24.58 & 23.57 & 25.64 & 27.93 \\
\hline $\begin{array}{c}\text { JS,exp } \\
(\mathrm{kg} / \\
\left.\mathrm{m}^{2} \mathrm{~h}\right)\end{array}$ & 6.23 & 6.58 & 6.82 & 7.16 & 7.64 & 7.68 & 7.86 & 8.34 & 8.84 \\
\hline $\begin{array}{c}\text { JS,sim } \\
(\mathrm{g} / \\
\left.\mathrm{m}^{2} \mathrm{~h}\right)\end{array}$ & 6.07 & 6.58 & 6.82 & 7.16 & 7.64 & 7.68 & 7.86 & 8.34 & 8.84 \\
\hline $\begin{array}{c}\text { Error } \\
\text { JW/JS } \\
(\%)\end{array}$ & $0.3 / 2.64$ & $0 / 0$ & $0 / 0$ & $0 / 0$ & $0 / 0$ & $0 / 0$ & $0 / 0$ & $0 / 0$ & $0 / 0$ \\
\hline
\end{tabular}

397

398

399

400

401

402

403

404

405

406

407

408

409

410

411

412

413

Table 2 presents the re-estimated water and salt permeabilities, using the iteration method in accordance with the nine cases at fixed structural parameter for coefficient mapping. Each A or B value is estimated individually. Thereby, the error value of $\mathrm{J}_{\mathrm{W}} / \mathrm{J}_{\mathrm{S}}$ is almost $0 \%$ except for case 1 by using iteration method. A, B and S in case 1 were estimated by using the method reported in [33].

As shown in Table 2, water and salt permeabilities increase by $161.41 \%$ and $149.72 \%$, respectively, as the inlet draw and feed temperatures increase from $20{ }^{\circ} \mathrm{C}$ to $40{ }^{\circ} \mathrm{C}$ ( 2 cases). A and $\mathrm{B}$ values are defined as a correlation equation, according to the inlet feed and draw temperatures.

To apply the mapped water and salt permeabilities data to our spatial variation model, the correlation of water and salt permeabilities (for the nine cases) are derived as two dimensional (2D) polynomial equations, using the commercial software MatlabR2017b. Fig. 11 shows the surface fitting of water and salt permeabilities versus the inlet draw and feed temperatures ranging from $20^{\circ} \mathrm{C}$ to $40^{\circ} \mathrm{C}$, respectively. The following correlations for $\mathrm{A}$ and $\mathrm{B}$ are obtained:

$$
A\left(T_{D}, T_{F}\right)=3.08472+0.14158 T_{F}-0.03625 T_{D}
$$

$+0.000267 T_{F}^{2}+0.00192 T_{F} T_{D}-0.00675 T_{D}^{2}\left(10^{-7} \mathrm{~m} / \mathrm{s} / \mathrm{bar}\right)$

$\left(R^{2}: 0.971\right)$

$$
B\left(T_{D}, T_{F}\right)=0.8385+0.04517 T_{F}+0.00427 T_{D}
$$

$$
-0.000115 T_{F}^{2}+0.000005 T_{F} T_{D}+0.000035 T_{D}^{2}\left(10^{-7} \mathrm{~m} / \mathrm{s}\right)
$$

$\left(R^{2}: 0.98441\right)$ 


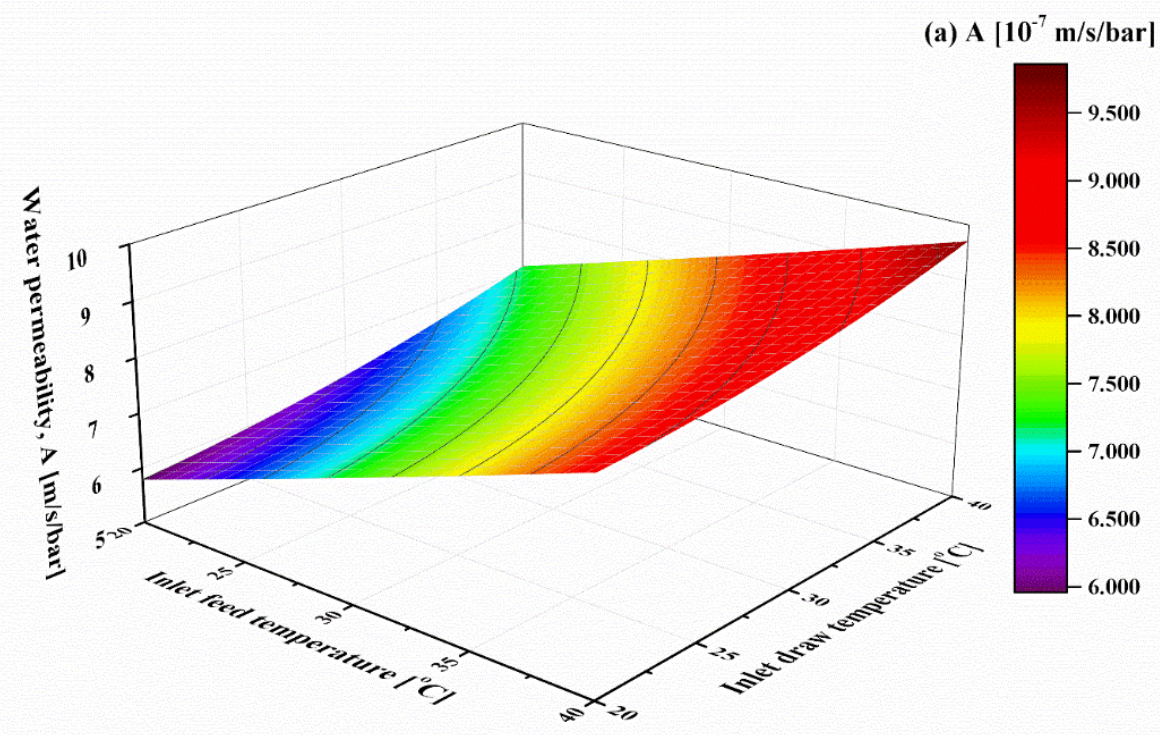

(b) $B\left[10^{-7} \mathrm{~m} / \mathrm{s}\right]$

415

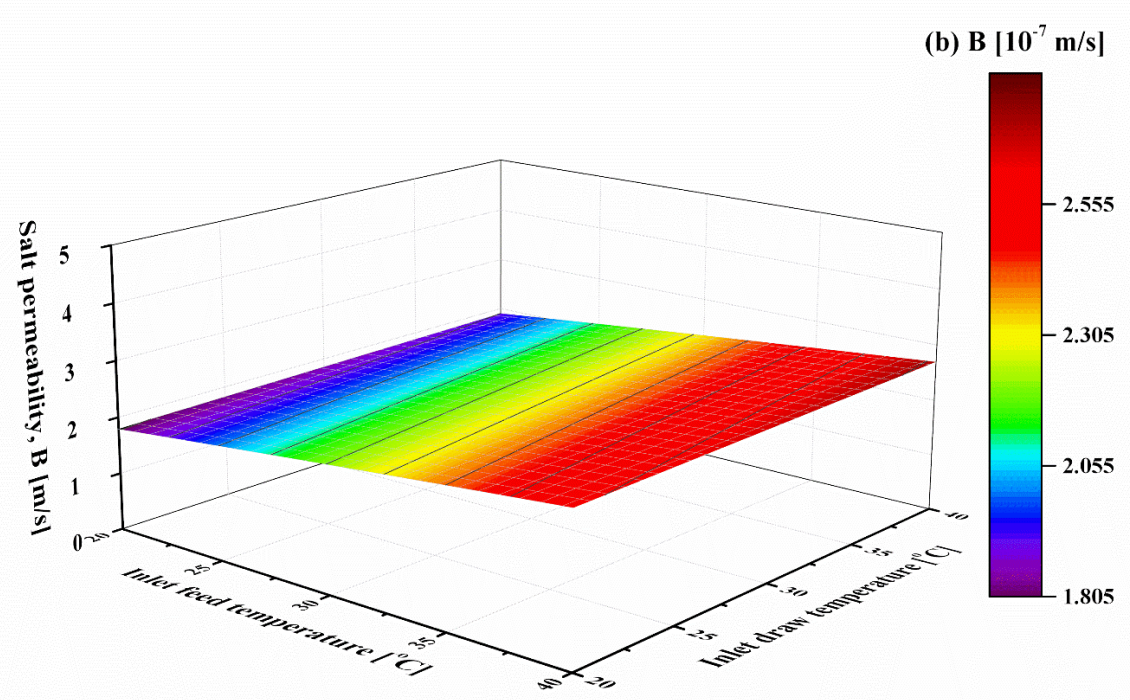

Figure 11. Surface fitting of (a) water and (b) salt permeabilities for inlet draw solution and feed temperatures varying from $20^{\circ} \mathrm{C}$ to $40^{\circ} \mathrm{C}$.

To validate the application of the derived correlations of water and salt permeabilities in the spatial variation model, the $\mathrm{J}_{\mathrm{w}}$ and the RSF are calculated by using the derived correlations in simulation and then the prediction result was compared with measured data. We find the measured and predicted data to be in good agreement, as shown in Fig. 12. The maximum error for the $\mathrm{J}_{\mathrm{w}}$ is $3.19 \%$ (case 2), and the maximum error for the RSF is $3.5 \%$ (case 7 ). These errors are probably mostly due to a limitation of the $2 \mathrm{D}$ polynomial curve fitting to the experimental 

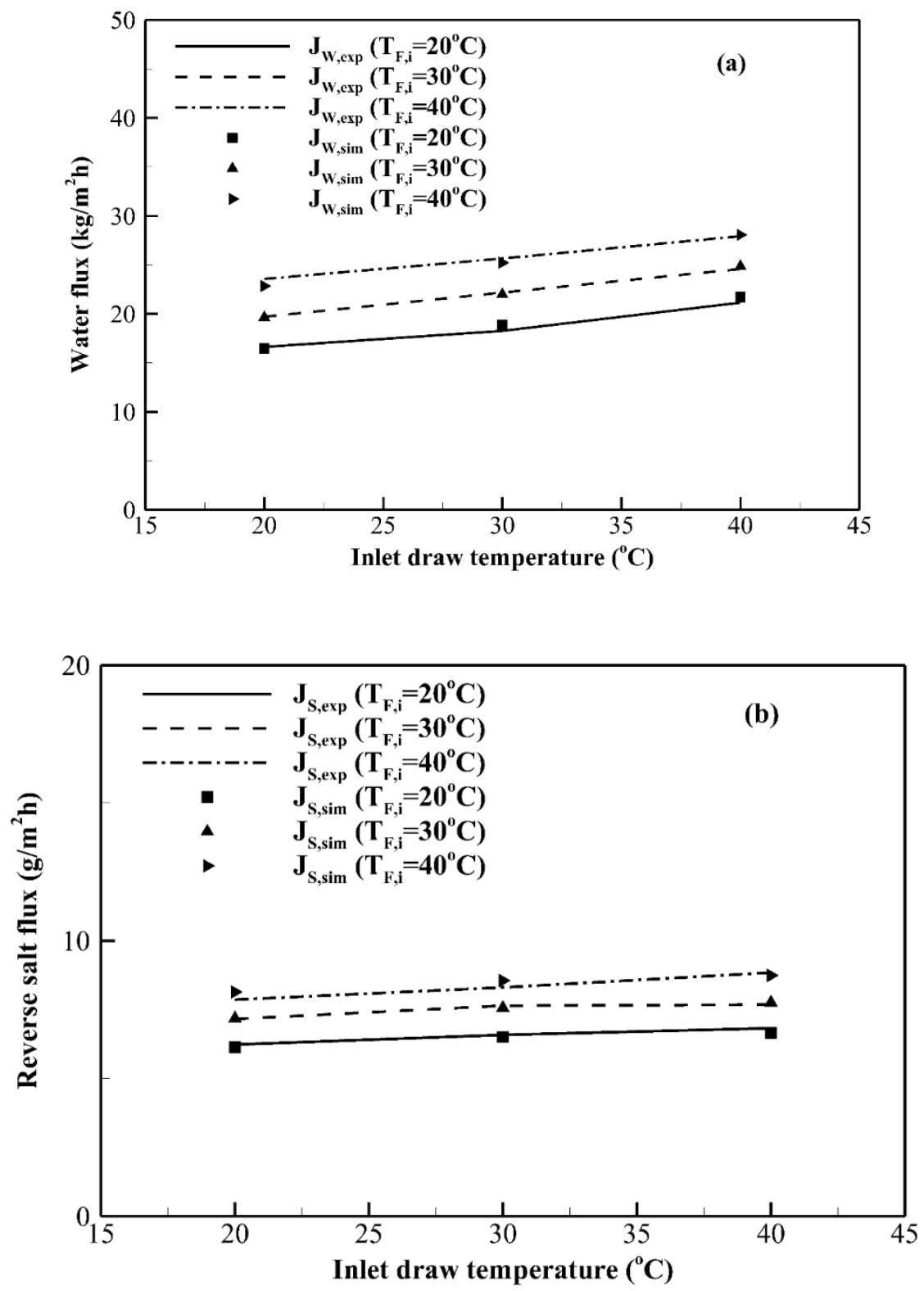

427

428

429

430

431

432

433

434

Figure 12. Influence of inlet feed and draw temperatures on (a) $J_{w}$ and (b)

RSF (measured and predicted results with mapped A and B).

\subsection{Comparison between length-averaged lumped model and spatial variation model}

To compare the length-averaged lumped model with the spatial variation model presented here, we perform simulation studies using the two different simulation models, at different channel widths ranging from $0.1 \mathrm{~m}$ to $0.3 \mathrm{~m}$, and for channel lengths ranging from $0.5 \mathrm{~m}$ to 2.5 
m. Simulations are performed at inlet draw and feed flow rates of $0.4 \mathrm{~L} / \mathrm{min}$, inlet draw and feed temperatures of $40{ }^{\circ} \mathrm{C}$, and at an inlet draw salinity of $35 \mathrm{~g} / \mathrm{L}$. Re-estimated correlations of water and salt permeabilities (see Section 4.3) are used with a fixed structural parameter (3.76E-4). The simulation results estimated by the length-averaged lumped model which was validated with experimental data was utilized for the comparison study with the spatial variation model from the Ref. [44]. At a channel length of $0.07 \mathrm{~m}$ for the short module (small effective area), the distribution of the concentration between the inlet and outlet of the feed and draw sides is negligible; this is because the total water and salt fluxes are much smaller than the inlet draw and feed flow rates. Therefore, we cannot observe a significant difference between the results obtained by the two different models, due to the very low (insignificant) dilution and concentration of the draw and feed sides. In other words, a higher $\mathrm{J}_{\mathrm{w}}$, as well as a higher RSF, can also produce a higher distribution of the concentration between the inlet and outlet. Additionally, this difference in concentration at the draw and feed sides can be intensified by the decrease of the inlet draw flow rate due to the mass or the salinity balance in the draw and feed sides.

Our next step is to investigate, using the two different simulation models, the effects of channel width on the $\mathrm{J}_{\mathrm{w}}$ and the RSF, at fixed inlet draw and feed volume flow rates of 0.4 $\mathrm{L} / \mathrm{min}$, for channel widths ranging from $0.1 \mathrm{~m}$ to $0.3 \mathrm{~m}$, a module channel length of $0.5 \mathrm{~m}$, inlet feed and draw temperatures of $40{ }^{\circ} \mathrm{C}$, and inlet draw and feed salinities of $35 \mathrm{~g} / \mathrm{L}$ and $0 \mathrm{~g} / \mathrm{L}$, respectively. Both inlet draw and feed velocities can be adjusted by varying the channel width when the fixed volume flow rate is used. The inlet draw and feed velocities can be decreased from $0.333 \mathrm{~m} / \mathrm{s}$ to $0.111 \mathrm{~m} / \mathrm{s}$, with an increase of the channel width from $0.1 \mathrm{~m}$ to $0.3 \mathrm{~m}$.

Fig. 13 presents the effect of channel width (from $0.1 \mathrm{~m}$ to $0.3 \mathrm{~m}$ ) on the predicted $\mathrm{J}_{\mathrm{w}}$ and RSF, calculated using the two different models at inlet draw and feed temperatures of $40{ }^{\circ} \mathrm{C}$, inlet draw and feed flow rates of $0.4 \mathrm{~L} / \mathrm{min}$, channel length of $0.5 \mathrm{~m}$, and inlet draw and feed salinities of the $35 \mathrm{~g} / \mathrm{L}$ and $0 \mathrm{~g} / \mathrm{L}$, respectively. The flux and RSF calculated with the lengthaveraged lumped model are higher than those obtained by our spatial variation model. In addition, the $\mathrm{J}_{\mathrm{w}}$ and RSF calculated by the length-averaged lumped model decrease, as the channel width increases. We find that the difference increases from $1.16 \%$ to $3.34 \%$ for the $\mathrm{J}_{\mathrm{w}}$, and from $1.22 \%$ to $3.38 \%$ for the RSF, with an increase in channel width of $0.2 \mathrm{~m}$ (from $0.1 \mathrm{~m}$ to $0.3 \mathrm{~m}$ ). This is because, in the FO process, the dilution and concentration of the feed and draw solutions between the inlet and outlet increase, as the inlet draw and feed velocities decrease 
471

(higher residence time). This is a parameter (variation of the velocity distribution along the module) that is not accurately predictable using the length-averaged lumped model. Both simulation models also show, from the above results, that the $\mathrm{J}_{\mathrm{w}}$ and RSF are not significantly changed when a high inlet volume flow rate and short channel length are used because the water and salt flux are still much lower than the inlet draw and feed flow rates.

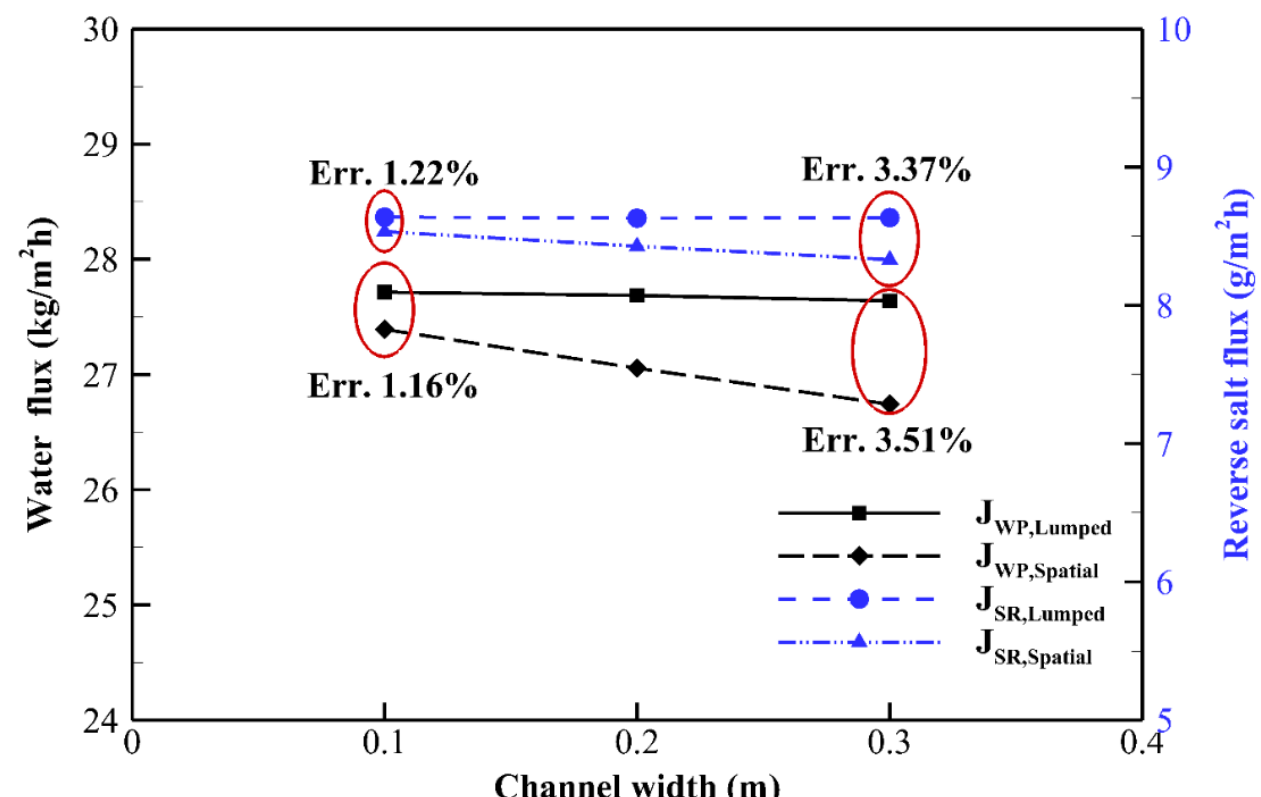

Figure 13. Influence of the channel width on (a) $J_{w}$ and (b) RSF estimated using the lengthaveraged based lumped model and our spatial variation model, at various channel widths, inlet draw and feed temperatures of $40^{\circ} \mathrm{C}$, inlet draw and feed flow rates of $0.4 \mathrm{~L} / \mathrm{min}$ and inlet draw and feed salinities of $35 \mathrm{~g} / \mathrm{L}$ and $0 \mathrm{~g} / \mathrm{L}$, respectively.

Figs. 14 (a) and (b) show the influence of the channel length on the flux and RSF, calculated using the two different models. The maximum difference of flux and RSF obtained using the two different models are $13.01 \%\left(\mathrm{~J}_{\mathrm{w}}\right)$ and $13.12 \%(\mathrm{RSF})$, respectively, at a channel length of $2.5 \mathrm{~m}$ and a width of $0.3 \mathrm{~m}$. This can be explained by the fact that the length-averaged based lumped model does not consider the variations of $\mathrm{J}_{\mathrm{w}}$ and RSF along the module as a result of the distribution of concentration. We find that the flux and RSF decrease with an increase in the total channel length due to the dilution and concentration effects along the draw and feed sides. Although the two models do not show any significant variation of the results obtained for the 
difference of $\mathrm{J}_{\mathrm{w}}$ and RSF, when using a small module (short channel length), we find this difference to be more pronounced as the channel length increases (e.g., large module such as multi-stage membrane distillation (MD) concept), mainly due to the decrease of the transmembrane osmotic pressure (small $\Delta \Pi$ ) and the temperatures at the membrane's feed and draw interfaces.
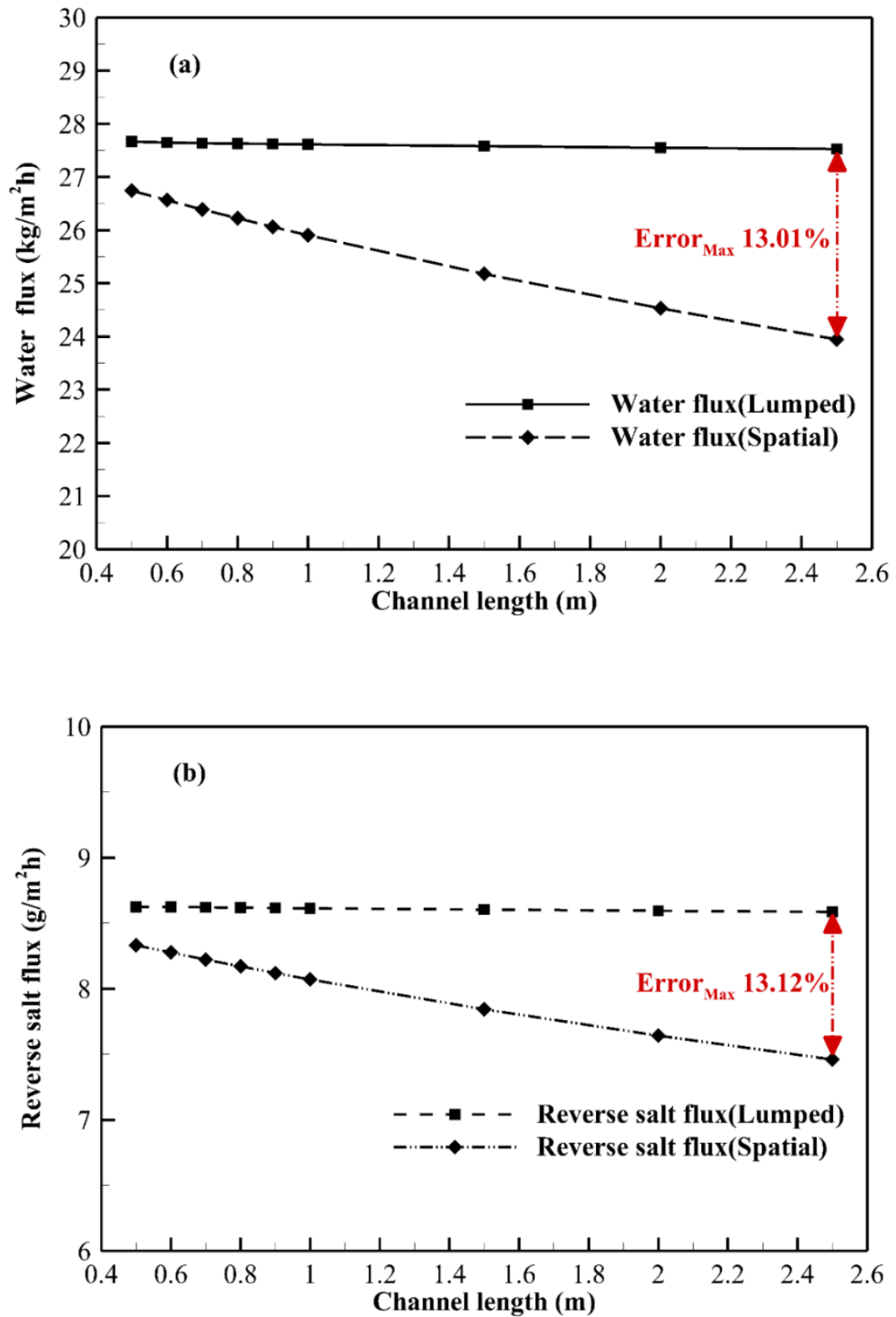

Figure 14. Influence of the channel length on (a) the $J_{\mathrm{w}}$ and (b) the RSF, estimated using both the length-averaged based lumped model and our spatial variation model, at a channel width of 0.3 
$\mathrm{m}$, inlet draw and feed temperatures of $40{ }^{\circ} \mathrm{C}$, inlet draw and feed flow rates of $0.4 \mathrm{~L} / \mathrm{min}$, and

inlet draw and feed salinities of $35 \mathrm{~g} / \mathrm{L}$ and $0 \mathrm{~g} / \mathrm{L}$, respectively.
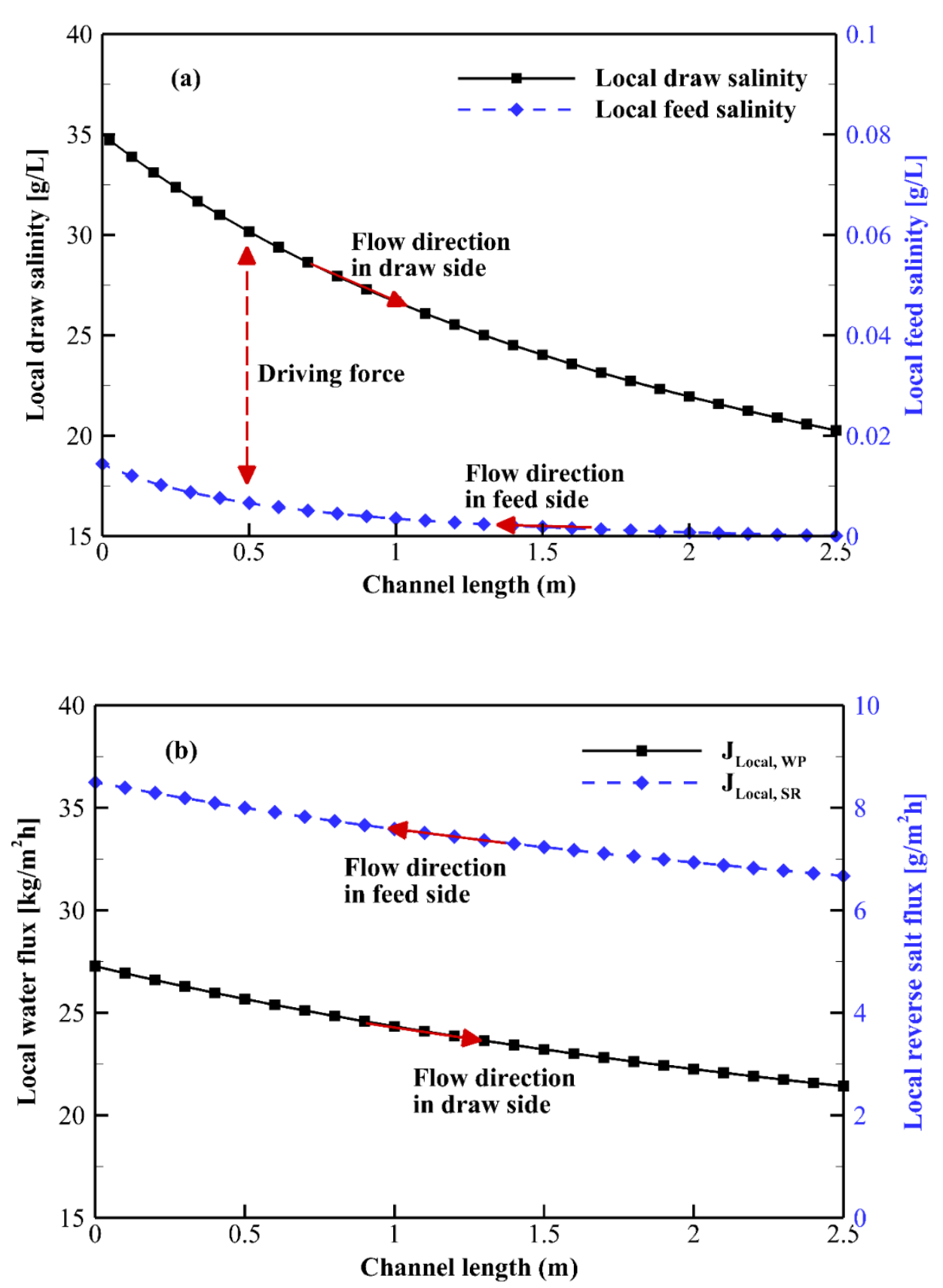

497

498

499

Figure 15. (a) Local draw and feed salinities and (b) local $J_{w}$ and RSF distributions along the module at a channel width of $0.3 \mathrm{~m}$ and length of $2.5 \mathrm{~m}$, inlet draw and feed temperatures of $40{ }^{\circ} \mathrm{C}$, inlet draw and feed flow rates of $0.4 \mathrm{~L} / \mathrm{min}$, and inlet draw and feed salinities of $35 \mathrm{~g} / \mathrm{L}$ and $0 \mathrm{~g} / \mathrm{L}$, respectively. 
The local draw, feed salinities, local $J_{\mathrm{w}}$ and RSF distributions are shown in Figs. 15 (a) and (b). The local draw salinity decreases from $35 \mathrm{~g} / \mathrm{L}$ to $20.25 \mathrm{~g} / \mathrm{L}$ along the module channel of 2.5 $\mathrm{m}$, due to the water permeation from the feed side, and at the same time the local feed salinity increases from $0 \mathrm{~g} / \mathrm{L}$ to $0.014 \mathrm{~g} / \mathrm{L}$, due to the RSF effect (Fig. 5a). As shown in Fig. 15 (b), the local $J_{\mathrm{w}}$ decreases from $27.26 \mathrm{~kg} / \mathrm{m}^{2} \mathrm{~h}$ to $21.41 \mathrm{~kg} / \mathrm{m}^{2} \mathrm{~h}$ and the local RSF increases from 6.67 $\mathrm{g} / \mathrm{m}^{2} \mathrm{~h}$ to $8.49 \mathrm{~g} / \mathrm{m}^{2} \mathrm{~h}$, due to a decrease of local driving force resulting from the dilution and concentration effects along the module channel in the draw and feed sides. The distribution of the local draw and feed concentrations are shown in Figs. 14 and 15. This study also reveals that the length-averaged lumped model is not appropriate to predict the performance of lower inlet velocities and long channels (large module such as multi-stage concept), hence it cannot give accurate simulation results to scale-up the FO process.

\section{Conclusions}

A new theoretical model has been developed and validated to describe the influence of spatial variations on the FO flux and RSF. The integrated model involves the thermophysical properties of the feed and the draw solutions and membrane, heat and mass transfer mechanism across the membrane, and the mass, momentum, salinity and energy balances for the draw and feed flows. Theoritical predictions are validated and compared with experimental data from the literature [44] as well as our own experimental data. All predictions are found to be in a good agreement with the experimental results. However, the relative error of the $\mathrm{J}_{\mathrm{w}}$ and RSF increases, as the inlet feed temperature increases. Both draw and feed transmembrane temperatures are calculated using our new spatial variation simulation model. This model reveals the effects of the temperatures of the adjacent bulk and feed membrane on the $\mathrm{J}_{\mathrm{w}}$ and RSF, in comparison with the effects from the bulk feed and draw temperatures. We also find that at a higher feed temperature near the membrane surface the flux and the RSF are always higher. An assessment of the influence of the feed and draw temperatures on the water and salt permeabilities show a $161.41 \%$ increase of the water permeability and $149.72 \%$ increase of the salt permeability as both the inlet draw and feed temperatures increase from $20{ }^{\circ} \mathrm{C}$ to $40{ }^{\circ} \mathrm{C}$.

We show that the length-averaged based lumped model overestimates the $\mathrm{J}_{\mathrm{w}}$ and RSF respectively by up to $13.01 \%$ (a decrease from $27.5 \mathrm{~kg} / \mathrm{m}^{2} \mathrm{~h}$ to $23.9 \mathrm{~kg} / \mathrm{m}^{2} \mathrm{~h}$ ) and $13.12 \%$, 
respectively, at channel length and width of $2.5 \mathrm{~m}$ and $0.3 \mathrm{~m}$, respectively, in comparison with our model that considers the spatial variations along the module channel.

Our work clearly demonstrates that the length-averaged based lumped model is not an appropriate simulation model to predict the performance of the FO process, at lower inlet feed velocities and large modules (long module channel or multi-stage concept) that are key parameters for the FO process scale-up. Moreover, the influence of temperature of draw and feed solutions on the FO water and salt permeability must be considered to accurately estimate the prediction results.

\section{Acknowledgments}

The research reported in this paper was supported by funding from King Abdullah University of Science and Technology (KAUST), Saudi Arabia. The authors acknowledge help, assistance and support from the Water Desalination and Reuse Center (WDRC) staff, and Mrs. Elisabeth M. Lutanie, Science Editor, Writer, Publication Services and Researcher Support at KAUST for editing the paper.

\section{Nomenclature}

A Water permeability coefficient of membrane $[\mathrm{m} / \mathrm{s} \cdot \mathrm{pa}]$

B Solute $(\mathrm{NaCl})$ permeability coefficient of membrane $[\mathrm{m} / \mathrm{s}]$

$\mathrm{C}_{\mathrm{p}} \quad$ Heat capacity $[\mathrm{J} / \mathrm{kg} \cdot \mathrm{K}]$

$\mathrm{c}_{\mathrm{D}, \mathrm{b}} \quad$ Bulk solute concentration of draw side $[\mathrm{mol} / \mathrm{L}]$

$\mathrm{c}_{\mathrm{F}, \mathrm{b}} \quad$ Bulk solute concentration of feed side $[\mathrm{mol} / \mathrm{L}]$

D Water diffusion coefficient $\left[\mathrm{m}^{2} / \mathrm{s}\right]$

$\mathrm{d}_{\mathrm{h}} \quad$ Hydraulic diameter [m]

$\mathrm{D}_{\mathrm{i}} \quad$ Density of isopropyl alcohol $\left[\mathrm{kg} / \mathrm{m}^{3}\right]$

$\mathrm{D}_{\mathrm{NaCl}}$ Bulk solute $(\mathrm{NaCl})$ diffusion coefficient $\left[\mathrm{m}^{2} / \mathrm{s}\right]$

$\mathrm{D}_{\mathrm{p}} \quad$ Density of the polymer $\left[\mathrm{kg} / \mathrm{m}^{3}\right]$

$\mathrm{dz} \quad$ Grid length [m]

F Convection heat transfer coefficient at feed side $[\mathrm{W} / \mathrm{mK}]$

Convection heat transfer coefficient at draw side $[\mathrm{W} / \mathrm{mK}]$

he Channel height [m] 


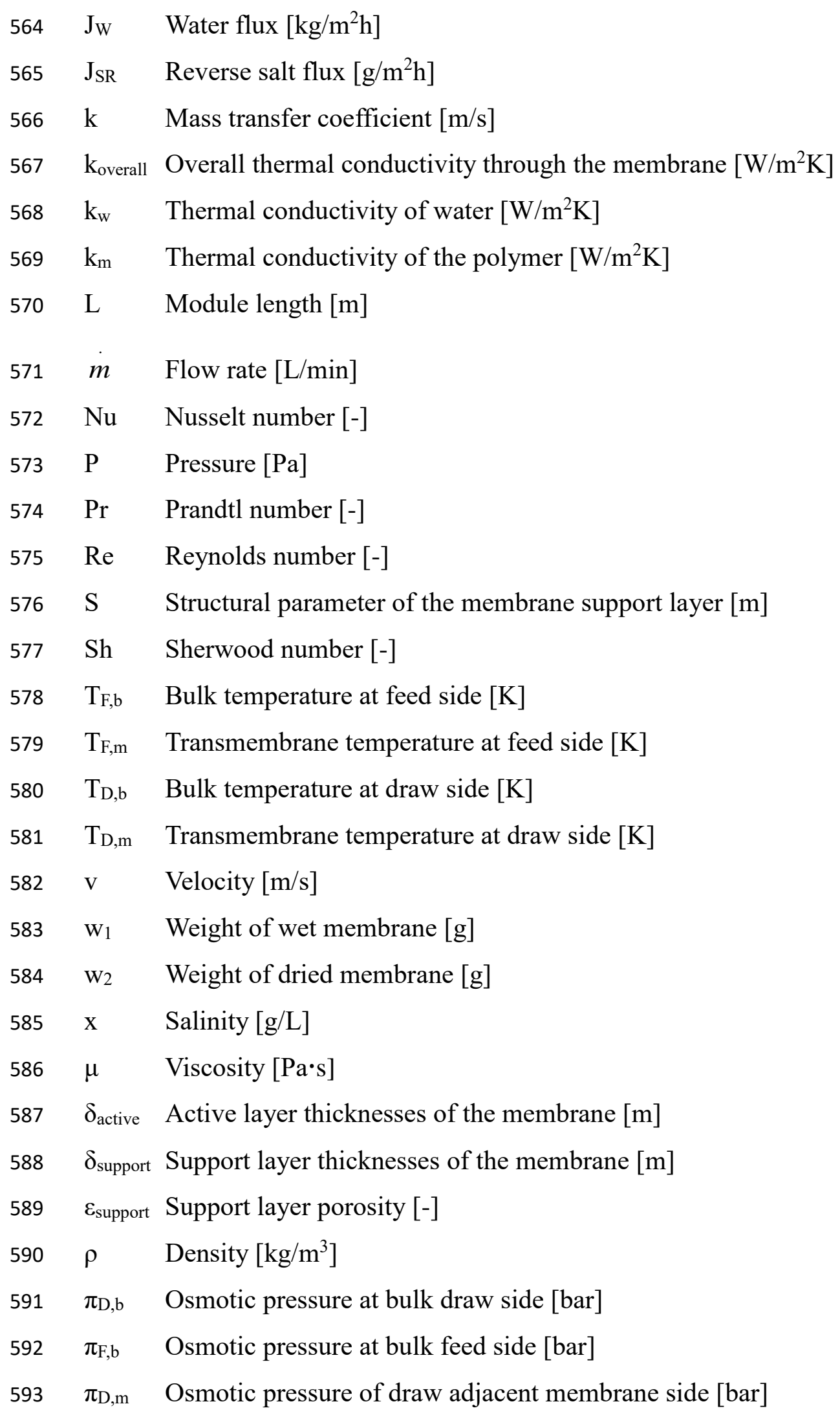


$\pi_{\mathrm{F}, \mathrm{m}} \quad$ Osmotic pressure of feed adjacent membrane side [bar]

$\tau \quad$ Tortuosity [-]

\section{References}

[1] N. Ghaffour, T.M. Missimer, G.L. Amy, Technical review and evaluation of the economics of water desalination: Current and future challenges for better water supply sustainability, Desalination, 309 (2013) 197-207.

[2] J.-G. Lee, W.-S. Kim, J.-S. Choi, N. Ghaffour, Y.-D. Kim, A novel multi-stage direct contact membrane distillation module: Design, experimental and theoretical approaches, Water Res., 107 (2016) 47-56.

[3] N. Ghaffour, J. Bundschuh, H. Mahmoudi, M.F. Goosen, Renewable energy-driven desalination technologies: A comprehensive review on challenges and potential applications of integrated systems, Desalination, 356 (2015) 94-114.

[4] R. Valladares Linares, Z. Li, V. Yangali-Quintanilla, N. Ghaffour, G. Amy, T. Leiknes, J.S. Vrouwenvelder, Life cycle cost of a hybrid forward osmosis - low pressure reverse osmosis system for seawater desalination and wastewater recovery, Water Res., 88 (2016) 225-234.

[5] N. Ghaffour, V.K. Reddy, M. Abu-Arabi, Technology development and application of solar energy in desalination: MEDRC contribution, Renewable and Sustainable Energy Reviews, 15 (2011) 4410-4415.

[6] G. Amy, N. Ghaffour, Z. Li, L. Francis, R.V. Linares, T. Missimer, S. Lattemann, Membranebased seawater desalination: Present and future prospects, Desalination, 401 (2017) 16-21.

[7] S. Li, Y. Kim, L. Chekli, S. Phuntsho, H.K. Shon, T. Leiknes, N. Ghaffour, Impact of reverse nutrient diffusion on membrane biofouling in fertilizer-drawn forward osmosis, J. Membr. Sci., 539 (2017) 108-115.

[8] J.E. Kim, S. Phuntsho, S.M. Ali, J.Y. Choi, H.K. Shon, Forward osmosis membrane modular configurations for osmotic dilution of seawater by forward osmosis and reverse osmosis hybrid system, Water Res., 128 (2018) 183-192.

[9] S. Shokrgozar Eslah, S. Shokrollahzadeh, O. Moini Jazani, A. Samimi, Forward osmosis water desalination: Fabrication of graphene oxide-polyamide/polysulfone thin-film nanocomposite membrane with high water flux and low reverse salt diffusion, Sep. Sci. Technol., 53 (2018) 573-583.

[10] S. Wu, S. Zou, G. Liang, G. Qian, Z. He, Enhancing recovery of magnesium as struvite from landfill leachate by pretreatment of calcium with simultaneous reduction of liquid volume via forward osmosis, Sci. Total Environ., 610-611 (2018) 137-146.

[11] B. Vital, J. Bartacek, J.C. Ortega-Bravo, D. Jeison, Treatment of acid mine drainage by forward osmosis: Heavy metal rejection and reverse flux of draw solution constituents, Chem. Eng. J., 332 (2018) 85-91.

[12] Q. Ge, G.L. Amy, T.-S. Chung, Forward osmosis for oily wastewater reclamation: Multicharged oxalic acid complexes as draw solutes, Water Res., 122 (2017) 580-590.

[13] E.A. Bell, T.E. Poynor, K.B. Newhart, J. Regnery, B.D. Coday, T.Y. Cath, Produced water treatment using forward osmosis membranes: Evaluation of extended-time performance and fouling, J. Membr. Sci., 525 (2017) 77-88.

[14] Y. Kim, Y.C. Woo, S. Phuntsho, L.D. Nghiem, H.K. Shon, S. Hong, Evaluation of fertilizerdrawn forward osmosis for coal seam gas reverse osmosis brine treatment and sustainable 
agricultural reuse, J. Membr. Sci., 537 (2017) 22-31.

[15] J.E. Kim, S. Phuntsho, L. Chekli, S. Hong, N. Ghaffour, T. Leiknes, J.Y. Choi, H.K. Shon, Environmental and economic impacts of fertilizer drawn forward osmosis and nanofiltration hybrid system, Desalination, 416 (2017) 76-85.

[16] L. Chekli, Y. Kim, S. Phuntsho, S. Li, N. Ghaffour, T. Leiknes, H.K. Shon, Evaluation of fertilizer-drawn forward osmosis for sustainable agriculture and water reuse in arid regions, Journal of Environmental Management, 187 (2017) 137-145.

[17] L. Chekli, J.E. Kim, I. El Saliby, Y. Kim, S. Phuntsho, S. Li, N. Ghaffour, T. Leiknes, H. Kyong Shon, Fertilizer drawn forward osmosis process for sustainable water reuse to grow hydroponic lettuce using commercial nutrient solution, Sep. Purif. Technol., 181 (2017) 18-28.

[18] L. Jin, Z. Wang, S. Zheng, B. Mi, Polyamide-crosslinked graphene oxide membrane for forward osmosis, J. Membr. Sci., 545 (2018) 11-18.

[19] D. Qin, Z. Liu, Z. Liu, H. Bai, D.D. Sun, Superior Antifouling Capability of Hydrogel Forward Osmosis Membrane for Treating Wastewaters with High Concentration of Organic Foulants, Environmental Science \& Technology, 52 (2018) 1421-1428.

[20] A.F. Faria, C. Liu, M. Xie, F. Perreault, L.D. Nghiem, J. Ma, M. Elimelech, Thin-film composite forward osmosis membranes functionalized with graphene oxide-silver nanocomposites for biofouling control, J. Membr. Sci., 525 (2017) 146-156.

[21] X. Wu, R.W. Field, J.J. Wu, K. Zhang, Polyvinylpyrrolidone modified graphene oxide as a modifier for thin film composite forward osmosis membranes, J. Membr. Sci., 540 (2017) 251260.

[22] X. Zhang, J. Tian, S. Gao, Z. Zhang, F. Cui, C.Y. Tang, In situ surface modification of thin film composite forward osmosis membranes with sulfonated poly(arylene ether sulfone) for antifouling in emulsified oil/water separation, J. Membr. Sci., 527 (2017) 26-34.

[23] S. Shokrollahzadeh, S. Tajik, Fabrication of thin film composite forward osmosis membrane using electrospun polysulfone/polyacrylonitrile blend nanofibers as porous substrate, Desalination, 425 (2018) 68-76.

[24] X.-Y. Chi, P.-Y. Zhang, X.-J. Guo, Z.-L. Xu, A novel TFC forward osmosis (FO) membrane supported by polyimide (PI) microporous nanofiber membrane, Appl. Surf. Sci., 427 (2018) 1-9. [25] T. Alejo, M. Arruebo, V. Carcelen, V.M. Monsalvo, V. Sebastian, Advances in draw solutes for forward osmosis: Hybrid organic-inorganic nanoparticles and conventional solutes, Chem. Eng. J., 309 (2017) 738-752.

[26] Y. Yang, M. Chen, S. Zou, X. Yang, T.E. Long, Z. He, Efficient recovery of polyelectrolyte draw solutes in forward osmosis towards sustainable water treatment, Desalination, 422 (2017) 134-141.

[27] B. Lian, G. Blandin, G. Leslie, P. Le-Clech, Impact of module design in forward osmosis and pressure assisted osmosis: An experimental and numerical study, Desalination, 426 (2018) $108-117$.

[28] S.-J. Im, H. Rho, S. Jeong, A. Jang, Organic fouling characterization of a CTA-based spiralwound forward osmosis (SWFO) membrane used in wastewater reuse and seawater desalination, Chem. Eng. J., 336 (2018) 141-151.

[29] S.-J. Im, J. Choi, J.-G. Lee, S. Jeong, A. Jang, Application of volume-retarded osmosis and low-pressure membrane hybrid process for water reclamation, Chemosphere, 194 (2018) 76-84.

[30] B. Corzo, T. de la Torre, C. Sans, R. Escorihuela, S. Navea, J.J. Malfeito, Long-term evaluation of a forward osmosis-nanofiltration demonstration plant for wastewater reuse in agriculture, Chem. Eng. J., (2018). 
[31] J.R. McCutcheon, M. Elimelech, Modeling water flux in forward osmosis: implications for improved membrane design, AlChE J., 53 (2007) 1736-1744.

[32] M. Taherian, S.M. Mousavi, Modeling and simulation of forward osmosis process using agent-based model system, Computers \& Chemical Engineering, 100 (2017) 104-118.

[33] A. Tiraferri, N.Y. Yip, A.P. Straub, S. Romero-Vargas Castrillon, M. Elimelech, A method for the simultaneous determination of transport and structural parameters of forward osmosis membranes, J. Membr. Sci., 444 (2013) 523-538.

[34] W.A. Phillip, J.S. Yong, M. Elimelech, Reverse draw solute permeation in forward osmosis: modeling and experiments, Environmental science \& technology, 44 (2010) 5170-5176.

[35] K. Lee, R. Baker, H. Lonsdale, Membranes for power generation by pressure-retarded osmosis, J. Membr. Sci., 8 (1981) 141-171.

[36] S. Loeb, L. Titelman, E. Korngold, J. Freiman, Effect of porous support fabric on osmosis through a Loeb-Sourirajan type asymmetric membrane, J. Membr. Sci., 129 (1997) 243-249.

[37] S.-J. You, X.-H. Wang, M. Zhong, Y.-J. Zhong, C. Yu, N.-Q. Ren, Temperature as a factor affecting transmembrane water flux in forward osmosis: steady-state modeling and experimental validation, Chem. Eng. J., 198 (2012) 52-60.

[38] M. R. Chowdhury, J. R. McCutcheon. Elucidating the impact of temperature gradients across membranes during forward osmosis: Coupling heat and mass transfer models for better prediction of real osmotic systems. Journal of Membrane Science 553 (2018) 189-199.

[39] T.Y. Cath, S. Gormly, E.G. Beaudry, M.T. Flynn, V.D. Adams, A.E. Childress, Membrane contactor processes for wastewater reclamation in space: Part I. Direct osmotic concentration as pretreatment for reverse osmosis, J. Membr. Sci., 257 (2005) 85-98.

[40] B.R. Babu, N. Rastogi, K. Raghavarao, Effect of process parameters on transmembrane flux during direct osmosis, J. Membr. Sci., 280 (2006) 185-194.

[41] S. Zhao, L. Zou, Effects of working temperature on separation performance, membrane scaling and cleaning in forward osmosis desalination, Desalination, 278 (2011) 157-164.

[42] M. Li, Y. Wan, Z. Gao, G. Xiong, X. Wang, C. Wan, H. Luo, Preparation and properties of polyamide 6 thermal conductive composites reinforced with fibers, Materials \& Design, 51 (2013) 257-261.

[43] R. Wang, L. Shi, C.Y. Tang, S. Chou, C. Qiu, A.G. Fane, Characterization of novel forward osmosis hollow fiber membranes, J. Membr. Sci., 355 (2010) 158-167.

[44] A. Tiraferri, N.Y. Yip, A.P. Straub, S.R.-V. Castrillon, M. Elimelech, A method for the simultaneous determination of transport and structural parameters of forward osmosis membranes, J. Membr. Sci., 444 (2013) 523-538.

[45] S. Phuntsho, S. Vigneswaran, J. Kandasamy, S. Hong, S. Lee, H.K. Shon, Influence of temperature and temperature difference in the performance of forward osmosis desalination process, J. Membr. Sci., 415 (2012) 734-744.

[46] M.F.A. Goosen, S.S. Sablani, S.S. Al-Maskari, R.H. Al-Belushi, M. Wilf, Effect of feed temperature on permeate flux and mass transfer coefficient in spiral-wound reverse osmosis systems, Desalination, 144 (2002) 367-372.

[47] Y. Kim, L. Francis, Z. Li, S. Li, R. Valladares, A.S. Alsaadi, H.S. Song, M. Abu-Ghdaib, G. Amy, N. Ghaffour, Osmotically and thermally isolated FO-MD integrated module, Environmental Science \& Technology 53 (2019) 3488-3498. 